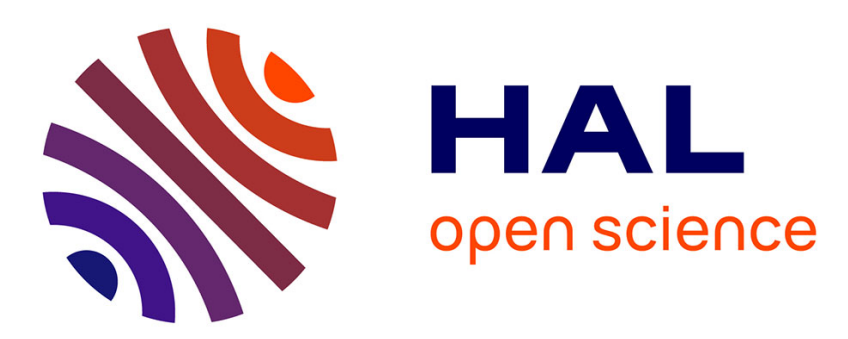

\title{
Investigation of the effect of aggregates' morphology on concrete creep properties by numerical simulations
}

\author{
F. Lavergne, Karam Sab, J. Sanahuja, Michel Bornert, C. Toulemonde
}

\section{To cite this version:}

F. Lavergne, Karam Sab, J. Sanahuja, Michel Bornert, C. Toulemonde. Investigation of the effect of aggregates' morphology on concrete creep properties by numerical simulations. Cement and Concrete Research, 2015, 71, pp.14-28. 10.1016/j.cemconres.2015.01.003 . hal-01134837

\section{HAL Id: hal-01134837 \\ https://hal-enpc.archives-ouvertes.fr/hal-01134837}

Submitted on 4 Sep 2015

HAL is a multi-disciplinary open access archive for the deposit and dissemination of scientific research documents, whether they are published or not. The documents may come from teaching and research institutions in France or abroad, or from public or private research centers.
L'archive ouverte pluridisciplinaire HAL, est destinée au dépôt et à la diffusion de documents scientifiques de niveau recherche, publiés ou non, émanant des établissements d'enseignement et de recherche français ou étrangers, des laboratoires publics ou privés. 


\title{
Investigation of the effect of aggregates'morphology on concrete creep properties by numerical simulations
}

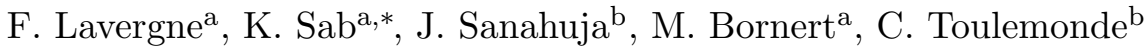 \\ ${ }^{a}$ Université Paris-Est, Laboratoire Navier (ENPC, IFSTTAR, CNRS) \\ 77455 Marne-la-Vallée Cedex, France \\ ${ }^{b}$ Département Mécanique des Matériaux et des Composants, EDF REDD, Site des Renardières, \\ Avenue des Renardières, 77818 Moret-Sur-Loing Cedex, France
}

\begin{abstract}
Prestress losses due to creep of concrete is a matter of interest for long term operations of nuclear power plants containment buildings. Experimental studies by Granger (1995) have shown that concretes with similar formulations have different creep behaviors. The aim of this paper is to numerically investigate the effect of size distribution and shape of elastic inclusions on the long term creep of concrete. Several microstructures with prescribed size distribution and spherical or polyhedral shape of inclusions are generated. By using the 3D numerical homogenization procedure for viscoelastic microstructures proposed by Šmilauer and Bažant (2010), it is shown that the size distribution and shape of inclusions have no measurable influence on the overall creep behavior. Moreover, a meanfield estimate provides close predictions. An Interfacial Transition Zone was introduced according to the model of Nadeau (2003). It is shown that this feature of concrete's microstructure can explain differences between creep behaviors.
\end{abstract}

Keywords: Modeling, Creep, Particle Size Distribution, Microstructure, Interfacial Transition Zone

\section{Introduction}

Concrete structures evolves due to time-dependent phenomena such as shrinkage and creep. Predicting basic creep is necessary to estimate the time-dependent prestress losses in thick structures such as nuclear containment buildings. For this purpose, experimental investigations were conducted by Granger [1] in order to assess the basic creep of six concretes with various formulations.

\footnotetext{
*Corresponding author. Tel: +33164153749

Email address: karam.sab@enpc.fr (K. Sab)
}

Postprint of Cement Concrete Research doi:10.1016/j.cemconres.2015.01.003 
According to this study, concretes with apparently similar formulation may exhibit different long term behaviors. For instance, the concrete from Flamanville and the one from Paluel have very similar formulation regarding cement composition, water to cement ratio and grain size distribution as shown in table [Tab. 1. Fillers were added to the concrete from Paluel so that the total amount of fine aggregates (smaller than $100 \mu \mathrm{m}$ ) was almost equal in these two concretes. However, the major difference between the two concretes is the nature of the aggregates : crushed granite (granodiorite) for Flamanville and semi-crushed sand-lime river gravel for Paluel. Actually, the time-dependent strains of these two concretes are very different as shown in figure [Fig. 1] : The average strain measured on concrete samples from Flamanville after three years of the same compressive loading was twice as much as the one measured on samples from Paluel. Since tests revealed comparable mechanical properties for aggregates, Granger [1] also measured the basic creep strains of the cementitious matrices without finding noticeable deviation. He concluded that the differences of overall creep properties were due to the aggregates (shape, mineralogy or interface with the cement paste).

\begin{tabular}{ccc} 
& Flamanville & Paluel \\
\hline$(12.5 / 25 \mathrm{~mm})$ & $700 \mathrm{~kg}$ & $700 \mathrm{~kg}$ \\
$(5 / 12.5 \mathrm{~mm})$ & $340 \mathrm{~kg}$ & $348 \mathrm{~kg}$ \\
$(0 / 0.8 \mathrm{~mm})$ & $170 \mathrm{~kg}$ & \\
$(0.1 / 0.5 \mathrm{~mm})$ & $485 \mathrm{~kg}$ & \\
$(0 / 5 \mathrm{~mm})$ & $140 \mathrm{~kg}$ & $722 \mathrm{~kg}$ \\
Filler Piketty & & $50 \mathrm{~kg}$ \\
Cement (St Vigor) & $375 \mathrm{~kg}$ & $375 \mathrm{~kg}$ \\
(CPA HP PM) & & \\
Water & $180 \mathrm{~kg}$ & $180 \mathrm{~kg}$ \\
BV40 plasticizer & $1.5 \mathrm{~kg}$ & $1.56 \mathrm{~kg}$ \\
\hline Young Modulus of aggregates & $51-65 \mathrm{GPa}$ & $65 \mathrm{GPa}$ \\
Young Modulus of concrete at 28 days & $31.9 \mathrm{GPa}$ & $38.4 \mathrm{GPa}$ \\
compressive strength $\mathrm{f}_{c}$ at 28 days & $50 \mathrm{MPa}-53.4 \mathrm{MPa}$ & $43.0 \mathrm{MPa}-52 \mathrm{MPa}$ \\
\hline
\end{tabular}

Table 1: Formulation of two concretes of Granger 1

Because experimental results are difficult to obtain, a natural way to perform parametric studies is to rely on models. The purpose of this paper is to numerically investigate the effect of size distribution and shape of inclusions on the long term creep of a matrix-inclusion material where the viscoelastic phase is the matrix. The matrix has the same behavior as a cement paste, the inclusions are perfectly bonded to the matrix and they have the elastic properties of aggregates.

One could use X-ray tomography images as inputs of 3D FFT-based compu- 


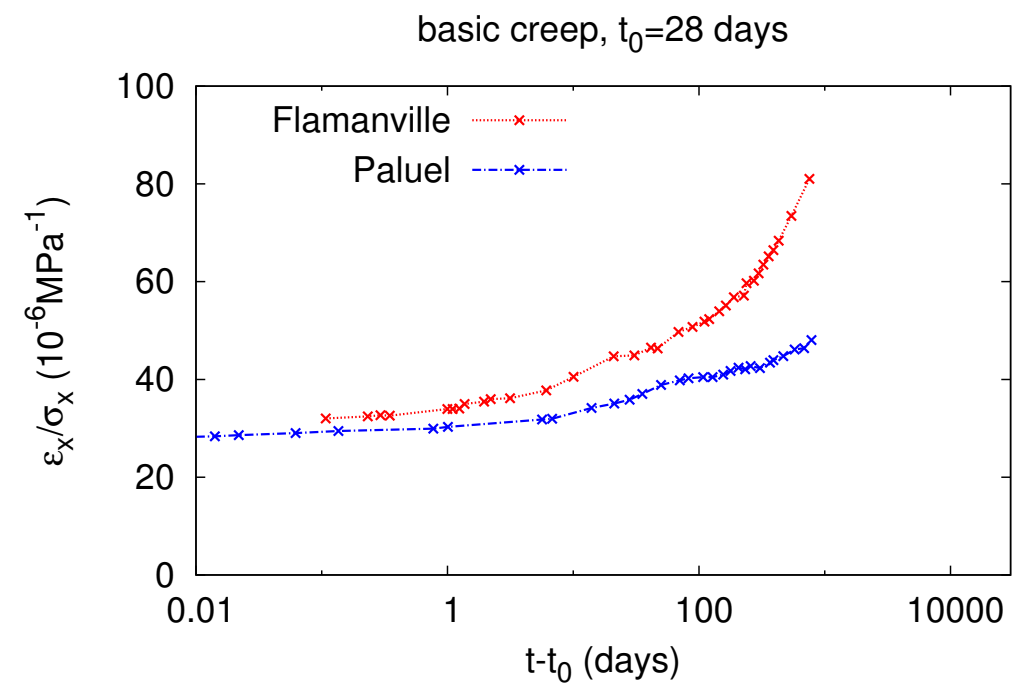

Figure 1: Results of uniaxial compressive creep tests reported by L. Granger [1]. Although the formulations of concretes from Flamanville and Paluel were comparable, the basic creep strain $\left(10^{-6} \mathrm{MPa}^{-1}\right.$ vs days) proved different. The compressive stress was $12 \mathrm{MPa}$ and the concrete was loaded at $t_{0}=28$ days.

tations [2] . This procedure has two drawbacks: the image must be segmented in order to differentiate the phases, and boundary effects may occur since the sample is not the unit cell of a periodic material. Filtering strategies have recently been defined to mitigate the effect of such boundary effects and get a macroscopically consistent estimate of the overall behaviour [3]. This study is focused on numerically generated periodic microstructures so as to tightly control the volume fraction of inclusions, their sizes and their shapes. The generation of several microstructures with prescribed grain size distribution and spherical or polyhedral shape of inclusions is made by dense sphere packing or Random Sequential Adsorption algorithm. The 3D numerical homogenization procedure for viscoelastic microstructures proposed by Šmilauer and Bažant 4 is used to compute the time-dependent response to a constant applied load. The Interface Transition Zone is described, the model of Nadeau [5] is recalled and the assumption to extend it to viscoelasticity are exposed. Then, the obtained results are compared to the predictions of mean-field homogenization.

In the first part of the paper, the microstructure generator is described, the $3 \mathrm{D}$ numerical homogenization method is introduced, some numerical tests are performed to validate and assess the performances of the simulations, the case of an Interfacial Transition Zone is exposed and its effect on the creep strain is numerically estimated. In the second part, the micromechanics methods are 
recalled and their predictions are compared to the numerical results. The paper ends with a discussion and a conclusion.

\section{Simulation of viscoelastic matrix-inclusion microstructures}

\subsection{Generation of matrix-inclusion microstructures}

In this section, the microstructure generator and the 3D numerical method for computing the overall viscoelastic response are presented. A matrix-inclusion microstructure is generated according to given volume fraction, sieve curve and shape of inclusions.

\subsubsection{Scope statement}

Some features are to be enforced in order to obtain a valuable matrix-inclusion microstructure generator :

- Inclusions are placed in a cubic cell and they should not overlap.

- The microstructure should be periodic.

- A tight control of the volume fraction, the size distribution and the shape of inclusions are required.

- High volume fractions of inclusions (> 50\%) are needed to represent realistic microstructures of concrete.

- The simulated material should be isotropic.

- The generator should run as fast as possible.

At least two methods may fulfill these requirements. The Random Sequential Adsorption (RSA) algorithm [6] is the simplest method to design and implement. Its ability to handle convex polyhedra makes it useful to assess the effect of shape of inclusions. A high volume fraction of inclusions (up to 68\%) may be reached for wide sieve curves. On the other hand, this method fails to simulate monodisperse grain size distribution for volume fraction greater than $30 \%$.

The other algorithm is the one of Lubashevky and Stillinger [7] which is dedicated to pack efficiently sets of ellipsoidal inclusions. In the case of monodisperse spheres, volume fraction up to $63 \%$ can be reached. To the authors' knowledge, there is no extension of this method to polyhedral inclusions. 


\subsubsection{Determination of the number of inclusions and their volumes}

Given the sieve curve (volume fraction vs particle diameter), the volume fraction of inclusions $f_{g}$ and the dimension $l$ of the cubic cell, the starting point, common to both methods, is the generation of the random number of the inclusions in the cubic cell and their volumes. The sieve curve is first approximated by a piecewise linear function of the equivalent diameters on twenty classes, each class representing $5 \%$ of the total volume of inclusions. The equivalent diameter of an inclusion, $d$, is given by $d=\sqrt[3]{\frac{6}{\pi} v}$, where $v$ is the volume of the inclusion. Each class must provide a volume $V_{5 \%}=0.05 \times l^{3} \times f_{g}$ of inclusions. On each class $i \in\{0,1, \ldots, 19\}$, the distribution of diameters is such that the approximated sieve curve $s(d)$ is an affine function of $d$ on the interval $\left[d_{i+1}, d_{i}\right.$ [ with $D_{\max }=d_{0}>d_{1}>\ldots>d_{20}=d_{\min }$. [Fig. 2]. The classes are filled one after another, starting from the class 0 of largest inclusions $\left[d_{1}, d_{0}\right.$ [ to the class 19 of the smallest inclusions $\left[d_{20}, d_{19}[\right.$. While the volume of the generated inclusions in class $i$ is less than $V_{5 \%}$, a new inclusion of diameter $d_{\text {picked }}$ is repeatedly generated in this class as explained hereafter.

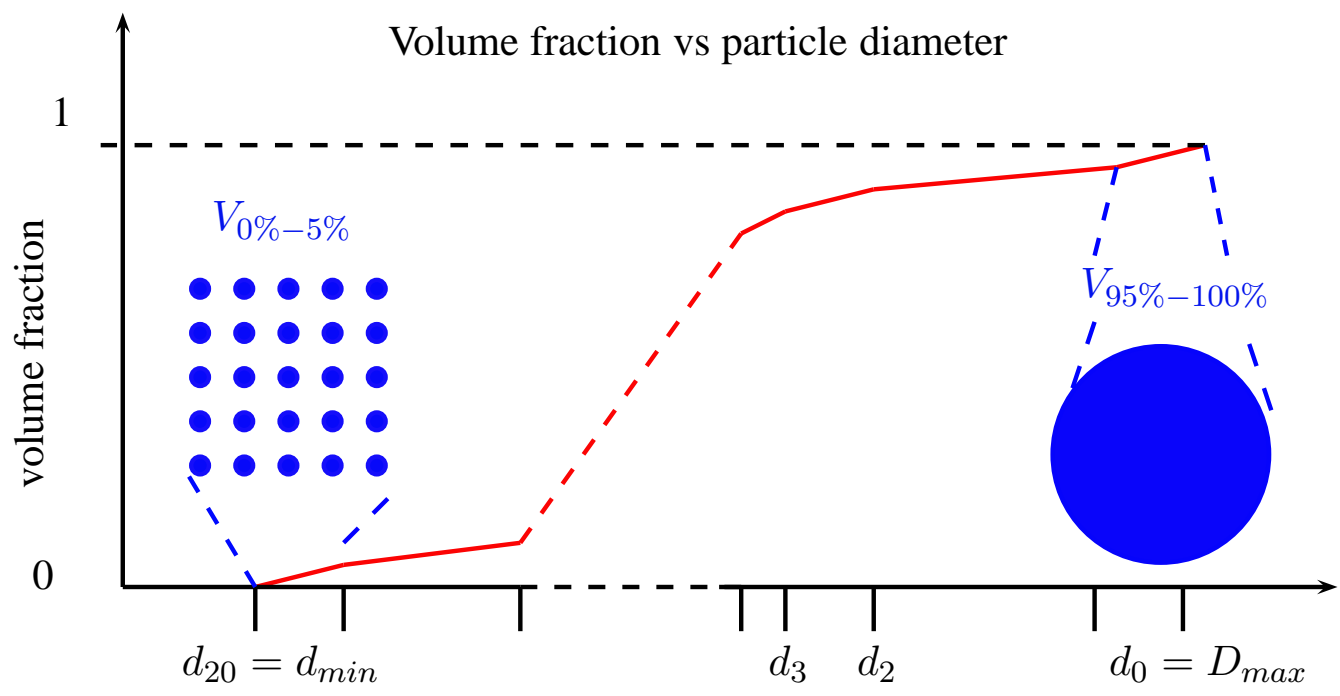

Particle diameter (mm)

Figure 2: The sieve curve : volume fraction vs particle diameter. This curve is approximated by a piecewise linear function on twenty classes, each class representing $5 \%$ of the total volume of inclusions.

Let $F_{i}(d)$ be the probability to pick in the class $i$ an inclusion of diameter lower than $d$. Since the sieve function is piecewise linear, $F_{i}^{\prime}(d) \frac{\pi}{6} d^{3}$ must be uniform. Taking into account $F_{i}\left(d_{i+1}\right)=0$ and $F_{i}\left(d_{i}\right)=1$, we find that $F_{i}$ is given by 
$F_{i}(d)=\frac{d^{-2}-d_{i+1}^{-2}}{d_{i}^{-2}-d_{i+1}^{-2}}$

Hence, $d_{\text {picked }}$ is generated by :

$d_{\text {picked }}=F_{i}^{-1}(R())=\left(d_{i+1}^{-2}+\left(d_{i}^{-2}-d_{i+1}^{-2}\right) R()\right)^{-\frac{1}{2}}$

where $F_{i}^{-1}$ is the inverse function of $F_{i}$ and $R()$ is the generator of the uniform random law on $[0,1[$

\subsubsection{Convex polyhedra and the RSA algorithm}

A convex polyhedron is generated aiming at controlling its shape [Fig 34 . A center is generated and a number of points is picked according to a Poisson law (parameter $\lambda>0$ ). Then, directions are selected on the unit sphere according to the uniform random law, and distances to the center are generated according to a log-normal law (parameters $\mu_{l} \in \mathbb{R}, \sigma_{l}>0$ ). The polyhedron is defined as the convex hull of those points which is computed through the $\mathrm{C}++$ interface of the Qhull software [8, 9].

Each convex polyhedron is generated according to the previously described procedure and is placed into the cubic cell avoiding overlapping with already generated polyhedra : its position is randomly picked in the cubic cell until non-overlapping is achieved. By putting the bigger inclusions first, high volume fraction may be reached. This method has already been used to generate concrete and mortar microstructures with spherical [10] or polyhedral inclusions [11]. Unlike [11], the computation of overlapping between polyhedra is performed analytically in the proposed generator. Indeed, overlapping between two polyhedra is computed thanks to the Gilbert-Johnson-Keerthi distance algorithm [12] as implemented in the Bullet physics library [13]. This procedure suppresses the exclusion-zone of one voxel adopted in [11] and it speeds up the computations. In addition, in order to limit the potential pair of polyhedra to be tested, the cubic cell is divided into sectors : two polyhedra can potentially overlap if they share the same sector. Moreover, each polyhedra is embedded in a rectangular bounding box because testing overlapping of boxes is much easier than testing overlapping of polyhedra. A polyhedron may be present in different sectors of the cubic cell in order to ensure periodicity.

The maximum reachable volume fraction depends on the size distribution and on inclusions' shape. A wide range of inclusions' sizes allows larger volume fractions. Simulating spherical inclusions is faster than simulating unaligned elongated inclusions with sharp edges. Artificial concrete microstructures with high volume fraction $(60-68 \%)$ and polyhedral inclusions can be built with the RSA method for some size distributions [Fig. 3]. In particular, the ratio between the largest inclusions' equivalent diameter to the smallest one must be less than 20. If this ratio is too large, the number of inclusions would become prohibitive. 
If this ratio is too small, reaching the given volume fraction would take too long or could not be achieved.
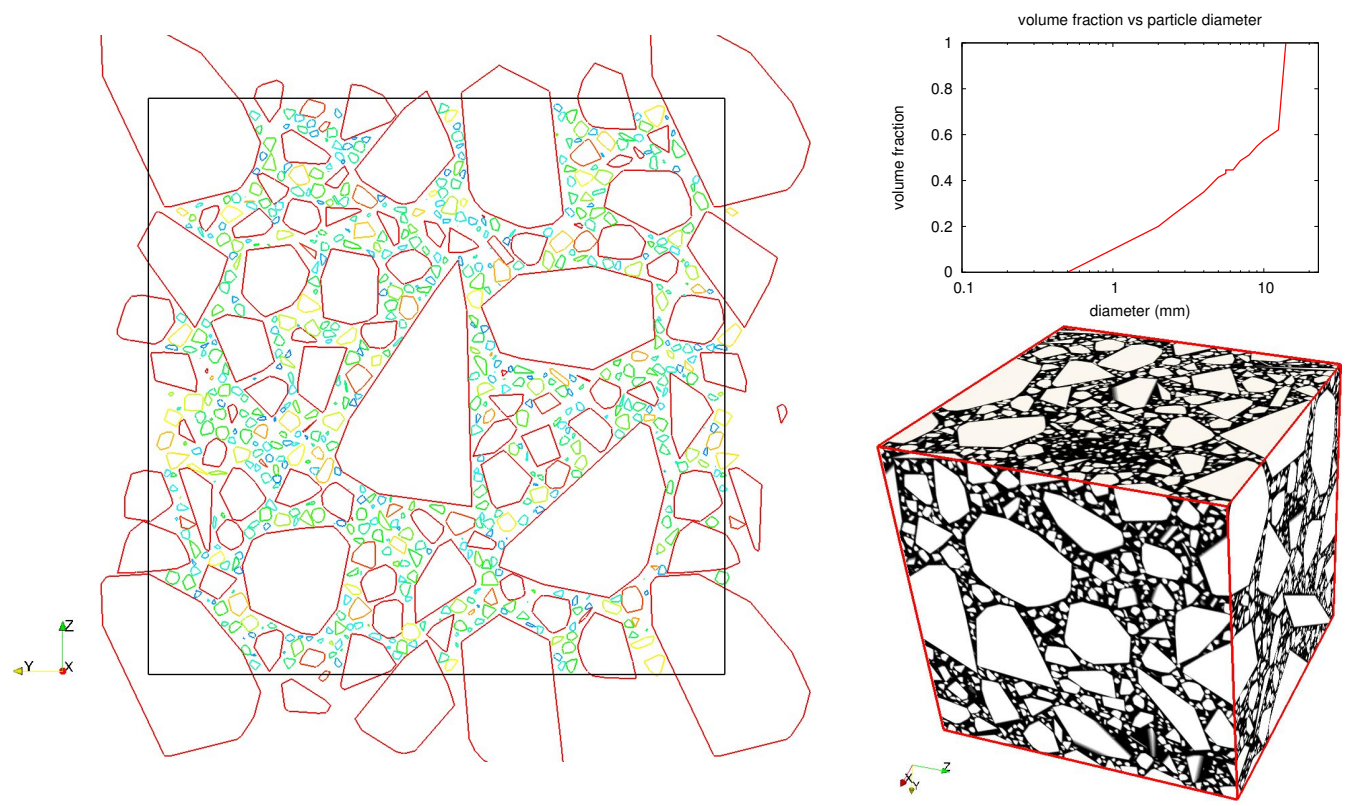

Figure 3: A section of a $4 \mathrm{~cm}$-wide sample of a concrete made of coarse sand $(d>0.5 \mathrm{~mm})$ and small gravel $(d<13.5 \mathrm{~mm})$ built by the RSA algorithm is shown. There are 28760 polyhedra in the cubic cell and the volume fraction is $68 \%$.
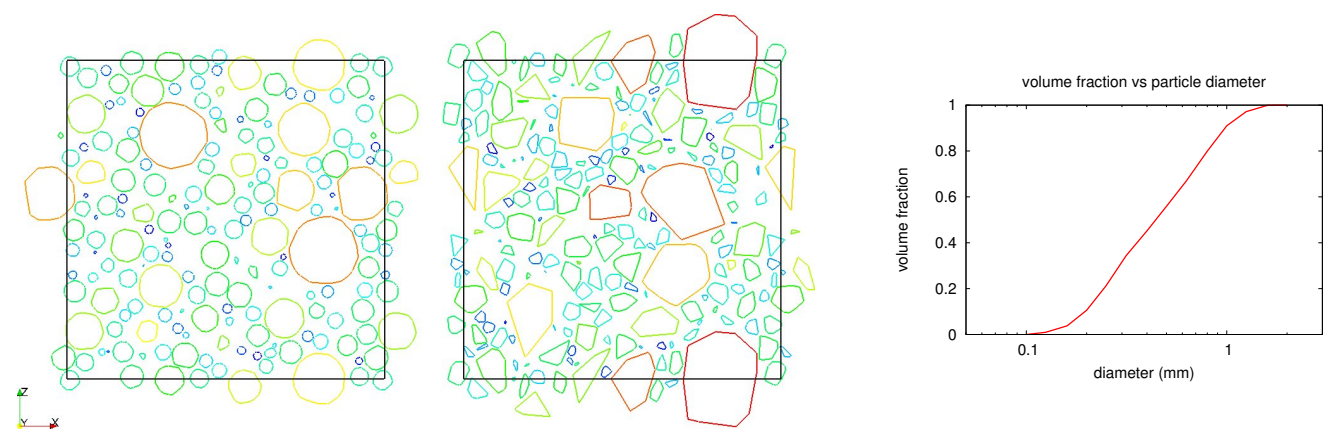

Figure 4: On the left, polyhedra are rather round whereas polyhedra feature sharp edges in the middle. The RSA algorithm has been used. The sieve curve of the corresponding mortar is presented on the right.

\subsubsection{Lubashevsky and Stillinger algorithm for spherical inclusions}

The RSA algorithm described above cannot achieve high volume fraction for monodisperse particles. For this reason, we use the Lubashevsky and Still- 
inger algorithm for generating matrix-inclusion microstructures with monodisperse spherical inclusions.

In our implementation, we use the algorithm described in [7] and [14] for simulating polydisperse packing of spherical inclusions. This dynamic, event-driven algorithm enables very high packing ratio of spheres. Seeds are placed in the cubic cell and their growth rate are chosen to comply with the size distribution. Each radius increases proportionally to time $t$ and each center moves with a constant velocity. As spheres collide, the algorithm changes their velocities to avoid overlapping. Thanks to uniform speeds and growth rates, collisions, or events, can be computed analytically. There is no need for time steps since nothing happen until the next event. Therefore the procedure jumps from one event to another and the program runs tremendously fast. This method has been extended to ellipsoids [15, 16], but this implementation is limited to spherical inclusions or sets of spheres. This algorithm has already been used to model composite materials in the range of elasticity [17].

\subsection{Numerical determination of the effective viscoelastic properties of heteroge- neous materials}

\subsubsection{The unit cell problem}

The aim of this section is to numerically determine the overall viscoelastic behavior of a matrix-inclusion microstructure where the inclusions are elastic and the matrix viscoelastic.

The strain tensor $\varepsilon(t)$ in a viscoelastic material depends on the history of stress tensor $\sigma(t)$. If the constitutive law is linear, the Boltzmann superposition principle states that the material properties are defined by a compliance function (fourth order tensor), $\mathbf{J}\left(t, t^{\prime}\right)$, such that :

$$
\varepsilon(t)=\int_{0}^{t} \mathbf{J}\left(t, t^{\prime}\right) \frac{d \sigma}{d t}\left(t^{\prime}\right) d t^{\prime}
$$

If the elapsed time since loading is the only relevant parameter, the material is non-aging :

$$
\mathbf{J}\left(t, t^{\prime}\right)=\mathbf{J}\left(t-t^{\prime}\right)
$$

The determination of the overall viscoelastic behavior of a periodic microstructure can be obtained by solving the following auxiliary problem on the periodic unit cell $V$.

$$
\begin{aligned}
& \operatorname{div} \sigma(x, t)=0 \quad x \in V \\
& \varepsilon(x, t)=\int_{0}^{t} \mathbf{J}\left(x, t, t^{\prime}\right) \frac{d \sigma}{d t}\left(x, t^{\prime}\right) d t^{\prime} \quad x \in V \\
& \varepsilon(x, t)=E(t)+\nabla^{s} u(x, t) \quad x \in V \\
& u(x, t) \quad \text { periodic } \quad x \in \partial V \\
& \sigma(x, t) \cdot n(x) \quad \text { skew-periodic } \quad x \in \partial V
\end{aligned}
$$

Here $E(t)$ is the time-dependent overall strain, $u(t, x)$ is the displacement field in $V, \nabla^{s} u(x, t)$ is its symmetric gradient, $\partial V$ is the boundary of $V$ and $n(x)$ is 
the outer normal to $\partial V$. Actually, $E(t)$ is the volume average of $\varepsilon(x, t)$ and we denote by $\Sigma(t)$ the volume average of $\sigma(x, t)$.

\subsubsection{Numerical discretizations}

We use the computational method of Šmilauer and Bažant in [4] developed for cementitious materials. This method which relies on the exponential algorithm $[18,19,20]$ is a time-iteration procedure to solve the viscoelastic problem for the case of steady loads. It features an integration of the constitutive equations on each time step assuming a constant stress rate. It enables the time step to grow exponentially when performing a relaxation (or creep) simulation. This method has recently made use of the FFT algorithm as the solver for the unit cell tangent problem [4, 21].

Let $\Delta \varepsilon(x)=\varepsilon\left(x, t_{i+1}\right)-\varepsilon\left(x, t_{i}\right), \Delta \sigma(x)=\sigma\left(x, t_{i+1}\right)-\sigma\left(x, t_{i}\right)$ and $\Delta u(x)=$ $u\left(x, t_{i+1}\right)-u\left(x, t_{i}\right)$ be respectively the strain, stress and displacement increment between time $t_{i}$ and $t_{i+1}$. These fields are solution of the following unit cell tangent problem :

$$
\begin{array}{rrr}
\operatorname{div} \Delta \sigma(x)=0 & x \in V \\
\Delta \varepsilon(x)=\int_{t_{i}}^{t_{i+1}} \mathbf{J}\left(x, t_{i+1}, t^{\prime}\right) \frac{d \sigma}{d t}\left(x, t^{\prime}\right) d t^{\prime}+\varepsilon_{0}(x) & x \in V \\
\Delta \varepsilon(x)=\Delta E+\nabla^{s} \Delta u(x) & x \in V \\
\Delta u(x) & \text { periodic } & x \in \partial V \\
\Delta \sigma(x) \cdot n(x) & \text { skew-periodic } & x \in \partial V
\end{array}
$$

where

$\varepsilon_{0}(x)=\int_{0}^{t_{i}}\left[\mathbf{J}\left(x, t_{i+1}, t^{\prime}\right)-\mathbf{J}\left(x, t_{i}, t^{\prime}\right)\right] \frac{d \sigma}{d t}\left(x, t^{\prime}\right) d t^{\prime}$

and

$\Delta E=E\left(t_{i+1}\right)-E\left(t_{i}\right)$.

$$
\mathbf{C}_{k}
$$

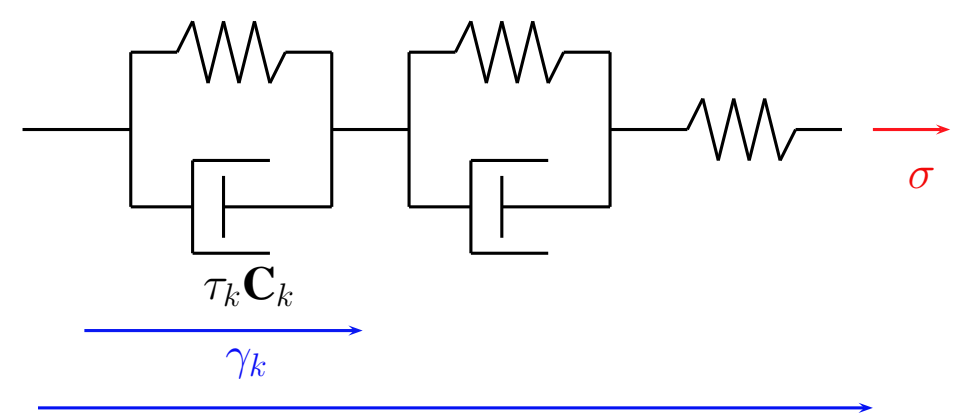

$\varepsilon$

Figure 5: The rheological model is made of a series of Kelvin chains

It is assumed that the stress rate $\frac{d \sigma}{d t}$ in the interval $\left[t_{i}: t_{i+1}\right]$ is constant and 
that the compliance corresponds to a series of Kelvin chains [Fig. 5] :

$$
\mathbf{J}\left(t-t^{\prime}\right)=\int_{t^{\prime}}^{t} \sum_{k=1}^{n} \frac{\tau}{\tau_{k}} e^{-\frac{\tau-t^{\prime}}{\tau_{k}}} \mathbf{C}_{k}^{-1} d \tau+\mathbf{C}_{0}^{-1}
$$

where $\mathbf{C}_{k}, k=0,1, \ldots, n$ are $n+1$ fourth-order elasticity tensors and $\tau_{k}, k=$ $1,2, \ldots, n$ are $n$ characteristic times. The integration of the constitutive equations on the time step gives the following incremental constitutive equation :

$$
\Delta \sigma(x)=\mathbf{C}_{t}^{i}(x)\left(\Delta \varepsilon(x)-\varepsilon^{i}(x)\right)
$$

where $\mathbf{C}_{t}^{i}(x)$ and $\varepsilon^{i}(x)$ are explicitly given by :

$$
\begin{aligned}
& \left(\mathbf{C}_{t}^{i}\right)^{-1}=\mathbf{C}_{0}^{-1}+\sum_{k=1}^{n}\left(1-\tau_{k} \frac{1-e^{-\frac{t_{i+1}-t_{i}}{\tau_{k}}}}{t_{i+1}-t_{i}}\right) \mathbf{C}_{k}^{-1} \\
& \varepsilon^{i}=\sum_{k=1}^{n} \tau_{k}\left(1-e^{-\frac{t_{i+1}-t_{i}}{\tau_{k}}}\right) \gamma_{k}^{i}
\end{aligned}
$$

where $\gamma_{k}^{i}$ are $n$ symmetric second-order strains corresponding to internal variables of Kelvin chains [Fig. 5. They are defined incrementally as $\gamma_{k}^{0}=0$ and for $i \geq 0$ :

$$
\gamma_{k}^{i+1}=\frac{1-e^{-\frac{t_{i+1}-t_{i}}{\tau_{k}}}}{t_{i+1}-t_{i}} \mathbf{C}_{k}^{-1} \Delta \sigma+e^{-\frac{t_{i+1}-t_{i}}{\tau_{k}}} \gamma_{k}^{i}
$$

Notice that the choice of a series of Kelvin chains combined with the above described exponential algorithm allows for the introduction of these internal variables. Hence, storing these few internal variables enables large computations (FEM or FFT).

To solve the unit cell tangent problem at each time step, a method is required. The FFT algorithm of $\mathrm{H}$. Moulinec and P. Suquet has proved a powerful tool to compute the elastic [22] and viscoelastic [23] response of a periodic microstructure. It takes digital images of materials and prestress as inputs. Both the basic [Alg, 1] 22] and the accelerated [Alg 22 24, 25] versions are written for this study. An isotropic reference material $\mathbf{C}_{0}^{*}$ is to be introduced and its Green operator $\Gamma^{0}$ is applied in the Fourier space. The loading can be either the prescribed macroscopic strain or the prescribed macroscopic stress as explained in [22].

Regarding implementation details, the MPI extension of the FFTW library [26, 27] and the PETSc library [28, 29, 30] are combined. The software routinely performs its computation on several processors on shared-memory machines as well as on clusters (Ivanhoe at EDF R\&D). Using less than twenty nodes and about 100-200 processes on this cluster, the size of the problem may be increased up to $700 \times 700 \times 700$ for elasticity and $400 \times 400 \times 400$ for viscoelasticity with 8 Kelvin chains and our computations last less than two hours (180 time steps). 


\subsubsection{Constituents' properties}

Long term behavior of concretes were experimentally identified by Granger in 11. Characteristic times $\tau_{k}$ and stiffness $\mathbf{C}_{k}$ of Kelvin chains correspond to a creep test of a concrete (Penly) loaded at 28 days. Eight characteristic times were introduced, one for each decade, from 0.002 days to 20000 days. Properties of the cement paste are assumed to be similar. To model a viscoelastic cimentitious matrix, the elastic and viscoelastic stiffnesses of a concrete were divided by three [Tab. 2]. Its Young modulus is $E_{\text {matrix }}=12 \mathrm{GPa}$, which is comparable to the measured ones of reconstituted cementitious matrices [1]. A reverse identification of these values could have been performed. All Poisson's ratios are assumed to be 0.2 . The behavior of inclusions is elastic isotropic (Young Modulus $E=60$ GPa and Poisson's ratio 0.2 ).

\begin{tabular}{ccc}
$\tau_{k}$ (days) & $\begin{array}{c}\text { Concrete, L. Granger } \\
\text { Young Modulus E, GPa }\end{array}$ & \multicolumn{2}{c}{ cement paste } \\
Young Modulus E, GPa
\end{tabular}

Table 2: Mechanical behavior of a concrete identified on a creep test [1 and the behavior of the defined cement paste. All Poisson ratios are assumed to be 0.2.

\subsubsection{Studied microstructures}

To explore the effect of grain size distribution and shape, the volume fraction was set to $63 \%$ and three different microstructures were defined :

- Unimodal : all inclusions are spherical and their diameters are equal. There are 150 inclusions for a volume of $8 \mathrm{~mm}^{3}$ and their radius is about $0.2 \mathrm{~mm}$.

- Bimodal : all inclusions are spherical. Two diameters coexist : about 0.2 $\mathrm{mm}$ and $1 \mathrm{~mm}$.

- Concrete : inclusions are polyhedra and their grain size distribution is described on [Fig. 3]. Regarding their shape, crushed inclusions correspond to convex hulls of about $\lambda=12$ points whose distances to center are picked according to a log-normal law $\left(\mu_{l}=0.08, \sigma_{l}=0.02\right)$ before scaling. 
With these parameters, the polyhedral inclusions are similar to inclusions used in concrete mixes. Indicators describing the inclusions' shape such as elongation ratio and flakiness ratio have been defined and measured on real samples of aggregates [31, 32, 33, 34. For an ellipsoidal inclusion with principal axes of lengths $a>b>c$, the elongation ratio is $a / b$ and the flakiness ratio is $c / b$. The average elongation ratio of the polyhedral inclusions used in our simulations is 1.08 and their average flakiness ratio is 0.8 . The elongation index and flakiness index correspond to the volume fraction of inclusions featuring respectively an elongation ratio greater than 1.8 and a flakiness ratio lower than 0.6. For normal mix design, the combined (flakiness + elongation) index for coarse aggregates must be limited to $25 \%$, for workability reasons [35]. In our simulations, the elongation index is less than $1 \%$ and the flakiness index is $11 \%$.

Examples of these microstructures are displayed on [Fig. 9].

\subsubsection{Validation of the numerical procedure}

To ensure the reliability of the method and its implementation, some basic tests were performed.

Time Discretization

Is the response of a homogeneous microstructure precisely computed ? The integration of the constitutive law on the time step may induce a numerical error. In the case of Kelvin chain, the result of a relaxation test is estimated by the Laplace-Carson transform and it serves as a reference to compute the relative numerical error for the cement paste (Fig 6). It should be emphasized that the long term stress of a series of Kelvin chain under a constant strain is steady. Therefore the numerical error due to time discretization vanishes. Different values of the rate $b=\frac{t_{i+2}-t_{i+1}}{t_{i+1}-t_{i}}$ of the geometric growth of the time steps were tested. In all our simulations, we chose the geometric growth $b=1.12$. Therefore, 180 unit cell tangent problems have to be solved to cover the range between $t-t_{0}=5 \times 10^{-6}$ days and $t-t_{0}=21900$ days where $t_{0}$ is the time of the initial loading.

Space discretization

In the case of heterogeneous microstructures, the discretization of the FFT grid also triggers numerical errors :

- The stress and strain field are stored per voxel which induces numerical errors. See [36] for further discussions about this issue.

- The heterogeneous microstructure is projected on a grid. Therefore, there is a loss of information about the local behavior of the material. A critical comparison of numerical methods working on conforming meshes or Cartesian grids was performed in the range of thermal conduction and linear elasticity at high phase contrast [37]. FFT solvers lead to very good 

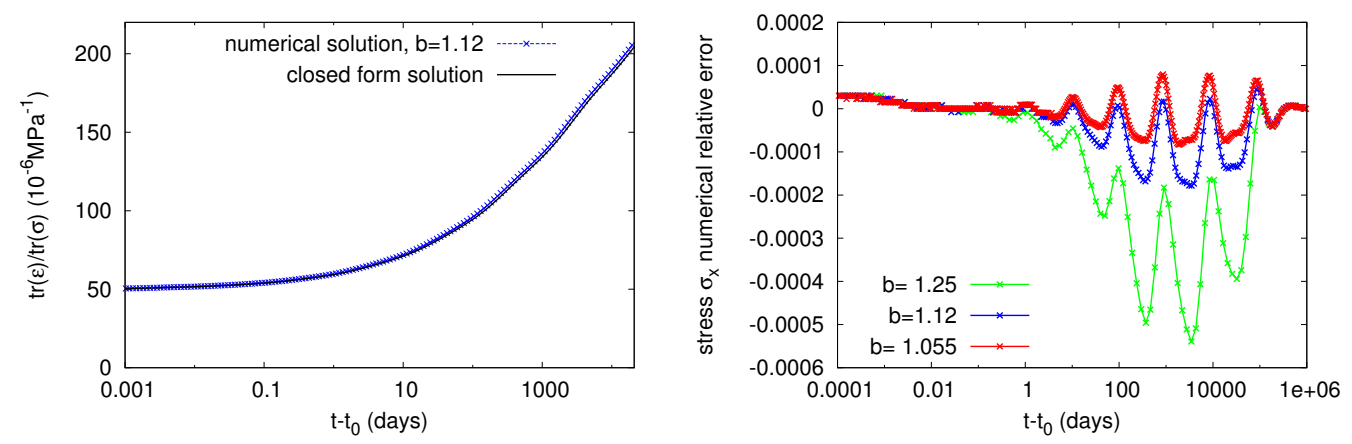

Figure 6: Time discretization. Left : Dilation strain during a hydrostatic creep test on a cement paste. The closed-form response and numerical estimate through the iterative procedure remain close. Right : Relative error on $\varepsilon_{x}$ during an uniaxial relaxation test on a homogeneous microstructure. The numerical error depends on the base $b$ for the geometric growth of the time step.

approximations of overall properties since extremely fine meshes can be considered.

In order to lower the error due to the projection on a grid, for each voxel, a local volume fraction based on 64 sensing points is computed and a Reuss-like constitutive law is computed and assigned to each voxel. Therefore, the microstructure is made of black voxels (pure matrix), white voxels (pure inclusions) and gray voxels (composite). To estimate the error due to discretization, the response of the unimodal microstructure with a volume fraction of $55 \%$ is computed at various resolutions [Fig. 7] 8. The use of a low contrast between the Young modulus of the phases $(<20)$, the ability of parallel FFT to deal with large grids and the choice of the Reuss bound for gray voxel lead to a mesh-independent overall response.

\subsubsection{Representative Volume Element}

It is well-known that the asymptotic overall response should not depend on the generated sample neither on the size of the unit cell which must be large enough to be representative of the microstructure ([38, 39] among others). For each microstructure defined in section 1.2.4, different size of the unit cell and many samples were generated. Numerical hydrostatic and shear creep tests are performed.

Two criteria were defined to ensure that the unit cell is a representative volume element :

- For a hydrostatic creep test, the unit-cell hydrostatic compliance at time $t$ is defined as $\frac{1}{3 K(t)}=\frac{\operatorname{tr}(\varepsilon(t))}{\operatorname{tr}(\sigma)}$ and for a shear creep test, the unit-cell shear 

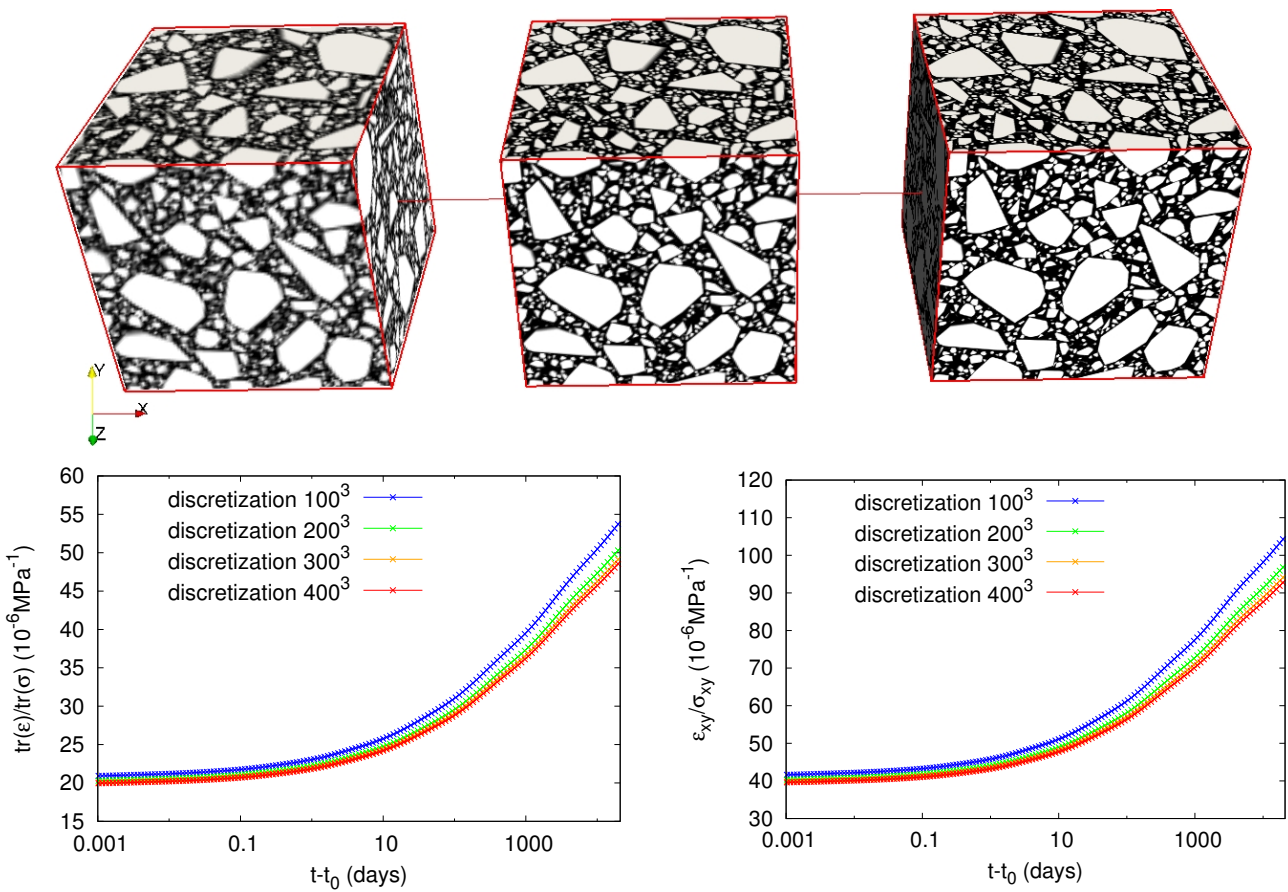

Figure 7: Top : One microstructure of concrete of size $40 \mathrm{~mm}$ made of $63 \%$ of inclusions at discretization $100^{3}, 200^{3}$ and $400^{3}$. Bottom : The delayed responses to hydrostatic (left) and shear(right) creep tests are computed.

compliance is $\frac{1}{2 G}(t)=\frac{\varepsilon_{x y}(t)}{\sigma_{x y}}$ The corresponding relative standard deviation of the compliance is defined as the ratio of the standard deviation to the average of the unit-cell compliance over the samples that were generated. It represents the statistical dispersion of the estimated overall time-dependent strains and it is expected to decrease as the size of the unit cell increases.

- An anisotropic indicator $a$ is defined to check that the unit-cell compliance is isotropic. For a hydrostatic creep test, it is defined as

$a=\sqrt{\frac{\left(\varepsilon_{x x}^{d e v}\right)^{2}+\left(\varepsilon_{y y}^{d e v}\right)^{2}+\left(\varepsilon_{z z}^{d e v}\right)^{2}+2 \varepsilon_{x z}^{2}+2 \varepsilon_{y z}^{2}+2 \varepsilon_{x y}^{2}}{(\operatorname{tr}(\varepsilon) / 3)^{2}}}$

where $\varepsilon^{d e v}$ is the deviatoric part of the overall strain. For a shear creep test, $\sigma_{x y}$ being the direction of loading, it writes :

$a=\sqrt{\frac{\varepsilon_{x x}^{2}+\varepsilon_{y y}^{2}+\varepsilon_{z z}^{2}+2 \varepsilon_{x z}^{2}+2 \varepsilon_{y z}^{2}}{\varepsilon_{x y}^{2}}}$

$a$ is positive and $a$ is null if and only if the overall strain corresponds to the response of an isotropic material. 

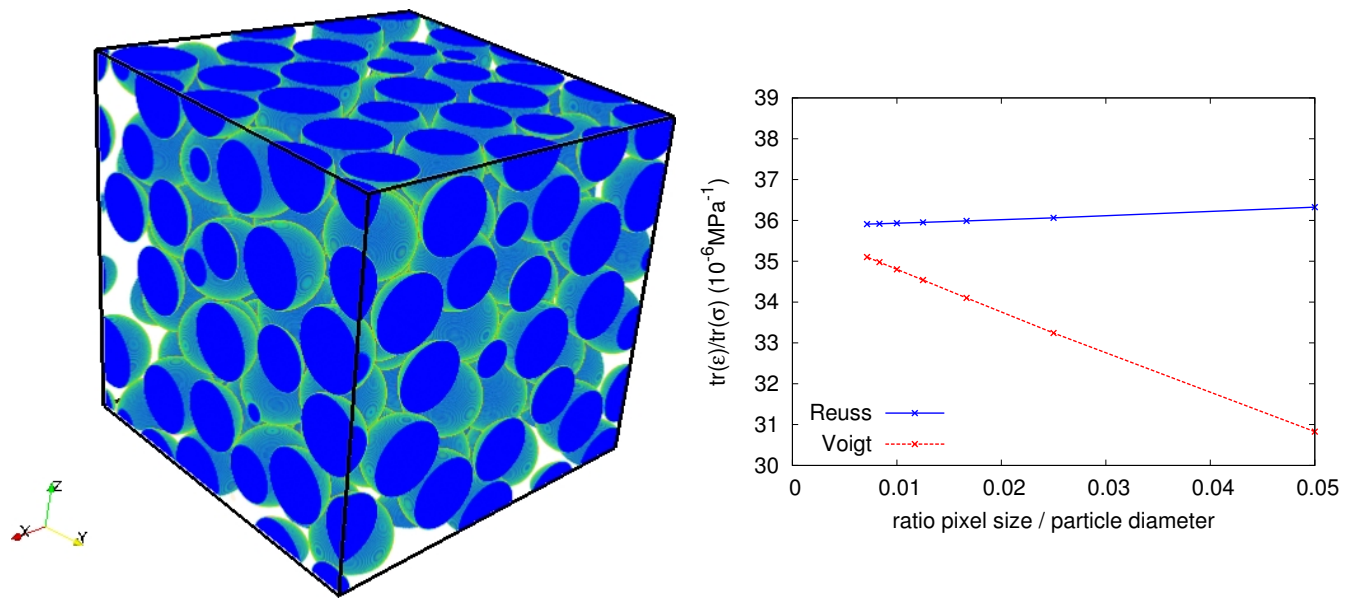

Figure 8: On the left : a microstructure made of $55 \%$ of spherical inclusions is discretized on a $500^{3}$ grid. On the right : Numerical elastic hydrostatic tests were performed on this microstructure $\left(E_{\text {inclusions }}=60 \mathrm{GPa}, E_{\text {matrix }}=6 \mathrm{GPa}\right)$. The smallest voxel size corresponds to a discretization on a $700^{3}$ grid. Assigning the Reuss-like behavior to gray (composite) voxels is less sensitive to discretization that the Voigt-like behavior.

The results of these tests are described in [Tab. 3]. The relative standard deviation of the estimated macroscopic compliances are very low and the overall response is isotropic. These features are obtained for cubic unit cells of concrete of $4 \mathrm{~cm} \times 4 \mathrm{~cm} \times 4 \mathrm{~cm}$ size, the largest inclusion diameter being less than $1.25 \mathrm{~cm}$ and the constituents' properties being those described in section 1.2.3. In the case of bimodal microstructures, a $2 \mathrm{~mm}$ unit cell, twice as large as the largest aggregates, was sufficient to retrieve a precise estimate of the overall strain. The frame of periodic homogenization allows precise results on small unit cells in the range of elasticity [40, 41]. Gal and Kryvoruck have performed 3D elastic computations on $50 \mathrm{~mm}$ large samples of concrete, the maximum diameter of aggregates being $15 \mathrm{~mm}$ [42] . Our simulations indicate that the size of the RVE remains small in the range of linear viscoelasticity, as long as the elastic contrast between phases is limited, while it may enlarge for phenomena like plasticity [43] or fatigue 44].

\subsubsection{Influence of grain size distribution and shape}

Responses to hydrostatic and shear creep tests are computed, the matrix being made of cement paste. The microstructures are those defined in section 1.2.4 on page 11. The volume fraction of inclusions is set at $63 \%$.

The overall time dependent strains remain close, even for very different microstructures[Fig. 9]. The sieve curve and the shape of inclusions have little effect on the overall viscoelastic behavior of the matrix-inclusion composite. Therefore, the only relevant parameter is the volume fraction of inclusions.

Thanks to 3D computations, stress concentrations can be estimated. During 


\begin{tabular}{|c|c|c|c|c|c|c|}
\hline microstructure & $\begin{array}{l}\text { size of } \\
\text { cubic } \\
\text { cell } \\
(\mathrm{mm})\end{array}$ & $\begin{array}{c}\text { maxi- } \\
\text { mum of } \\
\text { inclusion } \\
\text { diameter } \\
(\mathrm{mm})\end{array}$ & $\begin{array}{c}\text { average } \\
\text { compliance, } \\
\text { in } \\
10^{-6} \mathrm{MPa}^{-1}\end{array}$ & $\begin{array}{l}\text { compliance } \\
\text { relative } \\
\text { standard } \\
\text { deviation }\end{array}$ & $\begin{array}{l}\text { anisotropic } \\
\text { indicator } a\end{array}$ & $\begin{array}{c}\text { number of } \\
\text { tests }\end{array}$ \\
\hline \multicolumn{7}{|l|}{ hydrostatic test } \\
\hline \multicolumn{7}{|l|}{$t-t_{0}=0$ day } \\
\hline unimodal & 2 & 0.4 & 19.7 & 0.003 & 0.01 & 10 \\
\hline unimodal & 4 & 0.4 & 19.8 & 0.0005 & 0.003 & 5 \\
\hline bimodal & 2 & 1 & 19.8 & 0.0005 & 0.013 & 10 \\
\hline bimodal & 4 & 1 & 19.9 & 0.0003 & 0.004 & 5 \\
\hline concrete & 40 & 14 & 19.8 & 0.0005 & 0.012 & 10 \\
\hline \multicolumn{7}{|l|}{$\begin{array}{c}t-t_{0}=21900 \\
\text { days }\end{array}$} \\
\hline unimodal & 2 & 0.4 & 47.7 & 0.022 & 0.03 & 10 \\
\hline unimodal & 4 & 0.4 & 47.2 & 0.003 & 0.008 & 5 \\
\hline bimodal & 2 & 1 & 48.9 & 0.004 & 0.05 & 10 \\
\hline bimodal & 4 & 1 & 48.9 & 0.002 & 0.016 & 5 \\
\hline concrete & 40 & 14 & 48.9 & 0.003 & 0.04 & 10 \\
\hline \multicolumn{7}{|l|}{ shear test } \\
\hline \multicolumn{7}{|l|}{$t-t_{0}=0$ day } \\
\hline unimodal & 2 & 0.4 & 38.8 & 0.004 & 0.007 & 10 \\
\hline unimodal & 4 & 0.4 & 38.9 & 0.001 & 0.002 & 5 \\
\hline bimodal & 2 & 1 & 39.3 & 0.003 & 0.007 & 10 \\
\hline bimodal & 4 & 1 & 39.4 & 0.001 & 0.003 & 5 \\
\hline concrete & 40 & 14 & 39.3 & 0.002 & 0.006 & 10 \\
\hline \multicolumn{7}{|l|}{$\begin{array}{c}t-t_{0}=21900 \\
\text { days }\end{array}$} \\
\hline unimodal & 2 & 0.4 & 88.9 & 0.02 & 0.02 & 10 \\
\hline unimodal & 4 & 0.4 & 88.3 & 0.005 & 0.005 & 5 \\
\hline bimodal & 2 & 1 & 94.1 & 0.01 & 0.03 & 10 \\
\hline bimodal & 4 & 1 & 93.8 & 0.003 & 0.01 & 5 \\
\hline concrete & 40 & 14 & 92.7 & 0.006 & 0.02 & 10 \\
\hline
\end{tabular}

Table 3: For each kind of microstructure and different size of the unit cell, many samples are built and numerical hydrostatic and shear creep tests are performed. The relative standard deviation of the estimated macroscopic compliances are very low and the overall response is isotropic. 
a shear creep test $\sigma_{x y}=1 \mathrm{MPa}$, the instantaneous local shear stress is above $1.37 \mathrm{MPa}$ in $5 \%$ of the microstructure. After 60 years, the local shear stress is above $1.71 \mathrm{MPa}$ in $5 \%$ of the microstructure : for prescribed constant average stress, the stress distribution in the microstructure evolves with time. The matrix tends to relax while the stress increases in inclusions [Fig. 10]. The concrete and the bimodal microstructures cannot be distinguished based on the probability distributions of the stress component $\sigma_{x y}$ during a shear creep test [Fig. 10].

The limited heterogeneity between the inclusions and the matrix may be one of the reasons for the overall time dependent strains being so close. On the first time step, the elastic loading, the inclusions are 5 times stiffer than the matrix. On the last time step, 60 years after loading, the tangent behavior of the inclusions is 14 times stiffer than the one of the matrix.

As long as concrete is modeled as a matrix-inclusion microstructure, the discrepancies between creep strains of similar concretes cannot be attributed to the sieve curve or to the shape of inclusions. The description of concrete's microstructure must be refined.

Considering the cementitious matrix as homogeneous seems arguable as there is no strong scale separation in concrete. Considering a $40 \mathrm{~mm}$-wide sample of concrete and a $400^{3}$ discretization, each voxel is $100 \mu \mathrm{m}$ wide. At this scale, SEM images [45, 46, 47] clearly show that the behavior of the matrix may differ from one voxel to another due to fine aggregates, bundled partly unhydrated cement grains or a variable porosity [Fig. 11]. The assumption of a matrix-inclusion material might also be questionable for concrete since there sometimes exists an Interfacial Transition Zone between the inclusions and the cement paste. This feature is studied in the next section.

\subsubsection{Introducing an Interfacial Transition Zone}

The Interfacial Transition Zone is a $\approx 20 \mu \mathrm{m}$-thick layer of the cement paste that is more porous than the rest of the cement paste and has a different chemical composition [45]. It is due to the imperfect packing of cement grains $(<50 \mu \mathrm{m})$ on aggregates known as wall effect and it evolves during hydration. This feature may be observed on SEM images [45, 46, 47] and it might affect the mechanical properties [45, 48]. Garboczi and Berryman have successfully compared their analytical model to numerical elastic computations in the range of elasticity, the ITZ being introduced as effective layers around particles [49. For the elastic 3D computations of Gal and Kryvoruck [42, this porous zone is merged with the aggregates. This procedure increases the volume fraction of inclusions, but it decreases their elastic stiffness, especially for small aggregates if the thickness of the ITZ is taken as uniform. For the 2D finite element computations of Grondin [50], an effective mixed interphase around each aggregate is formed by the ITZ and by a volume fraction of the bulk cement paste. Micromechanics methods may 

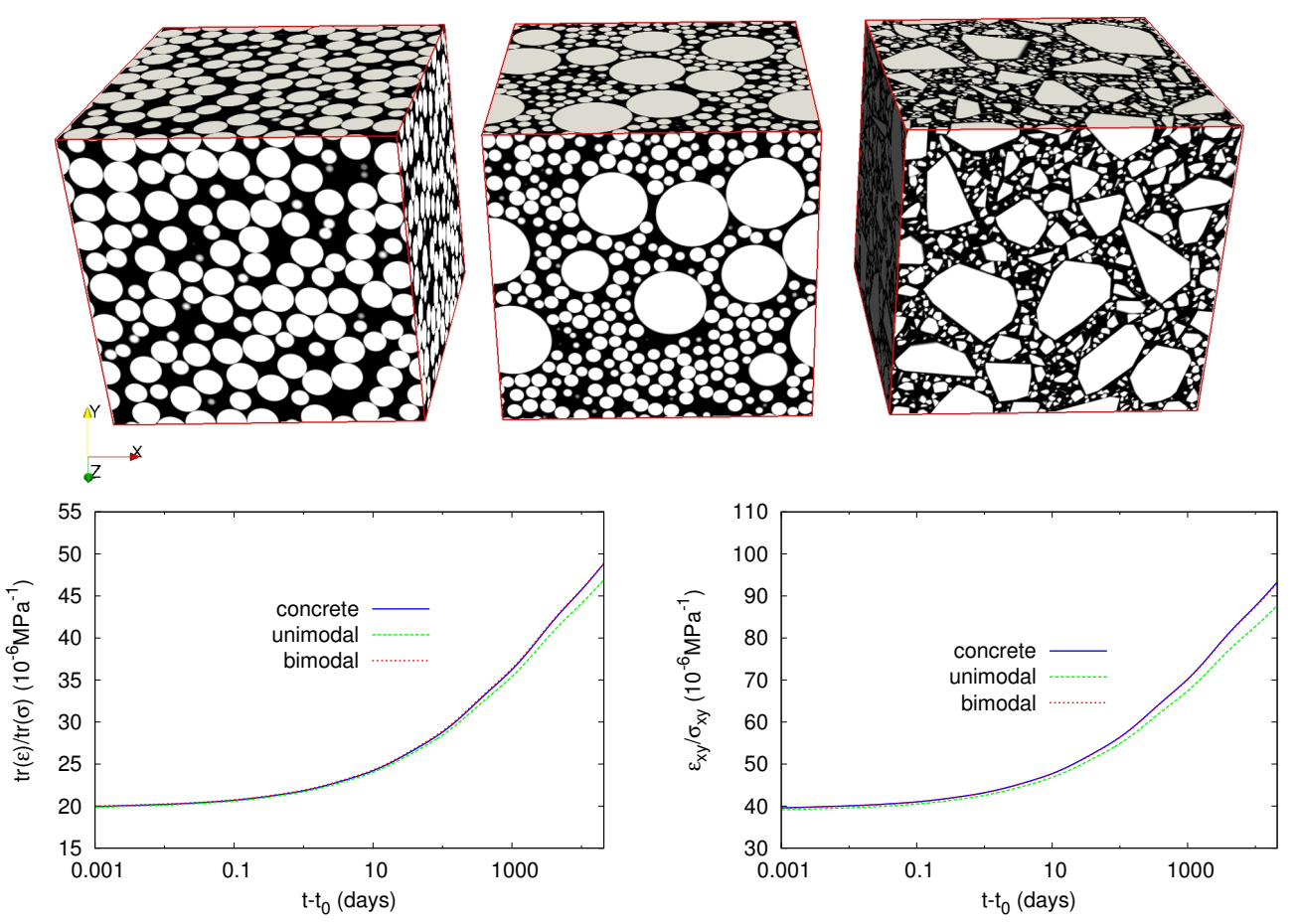

Figure 9: Viscoelastic responses to hydrostatic or shear macroscopic loadings. Various matrixinclusion microstructures with the same inclusions' volume fraction lead to very close timedependent strains. The unimodal microstructures seem to creep slightly less than the other microstructures. 

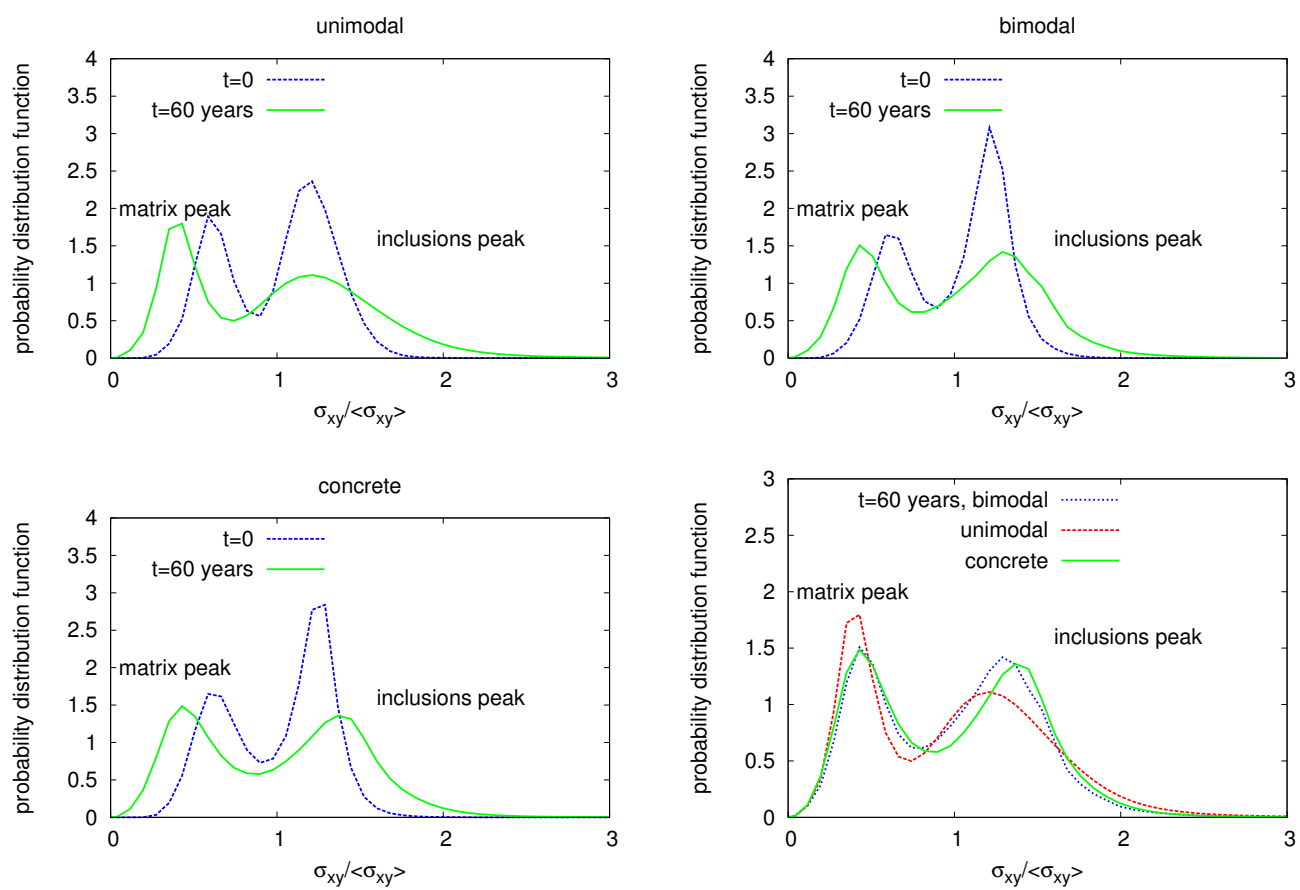

Figure 10: Probability distributions of a stress component $\sigma_{x y}$ during a shear creep test for different microstructures. On the top and bottom left, the relaxation of the matrix and the increase of stress in aggregates are displayed. On the bottom right, there are some differences between unimodal and concrete microstructures after 60 years.

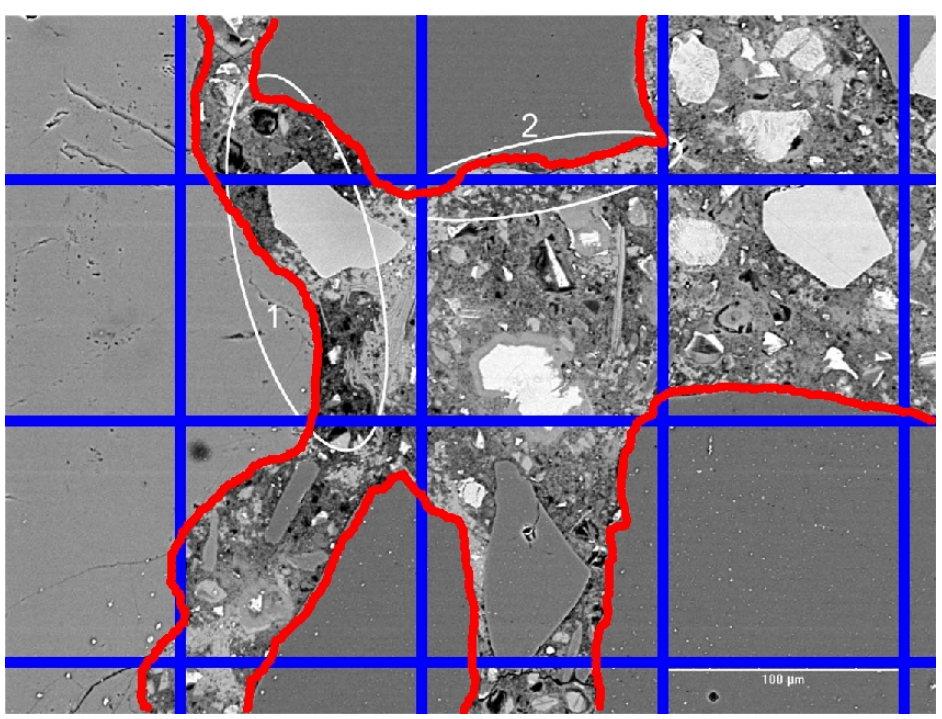

Figure 11: A blue $100 \mu \mathrm{m}$ grid is put on top of a SEM image from Scrivener [45. The red lines indicate the largest inclusions. The cement paste is clearly heterogeneous over a $100 \mu \mathrm{m}$ voxel. 
also take account of the ITZ as an effective layer surrounding inclusions [5, 49] or as an imperfect bonding between inclusions and matrix [51].

Representing the ITZ would not be possible a concrete scale since the size of the voxel would be $100 \mu \mathrm{m}$. Multiscale approaches may deliver a consistent way to set the behavior of composite voxels [3], since the finer details of the microstructure cannot be accurately described at concrete scale. To perform realistic homogenization computation, a $4 \mathrm{~mm}$-wide sample of a mortar was considered, so that $10 \mu \mathrm{m}$ details such as an ITZ can be pictured . The model of Nadeau [5] described hereafter was used to estimate the local behavior as a function of the distance to the nearest inclusion. Let $\delta$ be the thickness of the ITZ.

- The local volume fraction of cement $\alpha_{c}\left(d_{i}\right)$ depends on the distance to the nearest inclusion $d_{i}$

$$
\alpha_{c}\left(d_{i}\right)=\left\{\begin{array}{rr}
\bar{\alpha}_{c}\left(1-0.5\left(\frac{\delta-d_{i}}{\delta}\right)^{2}\right) & d_{i}<\delta \\
\bar{\alpha}_{c} & d_{i}>\delta
\end{array}\right.
$$

where $\bar{\alpha}_{c}$ is the volume fraction of cement far from the inclusions. As described below, it is computed for each microstructure so that the overall water to cement ratio $w / c$ is equal to 0.48 .

Let $f\left(d_{i}\right) \delta d$ be the volume fraction of the cementitious matrix located at a distance of the nearest inclusion between $d_{i}$ and $d_{i}+\delta d . f\left(d_{i}\right)$ is numerically estimated for each microstructure. The following equality stands :

$$
w / c=\frac{\int_{0}^{\infty} \alpha_{w}(x) f(x) d x}{\rho_{c} \int_{0}^{\infty} \alpha_{c}(x) f(x) d x}
$$

where $\rho_{c} \approx 3.15$ is the density of cement and $\alpha_{w}\left(d_{i}\right)$ is the local volume fraction of water. If cement and water are the only constituents of the cement paste, $\alpha_{w}\left(d_{i}\right)+\alpha_{c}\left(d_{i}\right)=1$ for all $d_{i}$ and :

$$
\int_{0}^{\infty} \alpha_{c}(x) f(x) d x=\frac{1}{1+\rho_{c} w / c}
$$

and finally :

$$
\bar{\alpha}_{c}=\left(\left(1+\rho_{c} w / c\right)\left(\int_{0}^{\delta}\left(1-0.5\left(\frac{\delta-x}{\delta}\right)^{2}\right) f(x) d x+\int_{\delta}^{\infty} f(x) d x\right)\right)^{-1}
$$

- The elastic behavior $\mathbf{C}_{0}$ as a function of the local water to cement ratio, equal to $\frac{\alpha_{w}}{\rho_{c} \alpha_{c}}$, is provided by fit on experimental tests, as reported by Nadeau [52]. To set viscoelastic parameters, two assumptions were made.

1. The viscoelastic Poisson's ratio of each Kelvin chain is the same as the elastic one. 
2. The effect of water to cement ratio on the elastic and viscoelastic parameter are identical : $\mathbf{C}_{k}=A_{k} \mathbf{C}_{0}\left(\frac{\alpha_{w}}{\rho_{c} \alpha_{c}}\right)$ where $A_{k}$ is a constant. For instance, if increasing the water to cement ratio from 0.48 to 0.55 decreases the elastic Young Modulus $\left(\mathbf{C}_{0}\right)$ by $30 \%$, then the drop of all viscoelastic modulus of Kelvin chains $\mathbf{C}_{k}, k \geq 1$ is also $30 \%$.

The assumption $\mathbf{C}_{k}=A_{k} \mathbf{C}_{0}\left(\frac{\alpha_{w}}{\rho_{c} \alpha_{c}}\right)$ holds true if the cement paste is considered as a porous material which solid phase is a non aging linear viscoelastic material with a uniform Poisson's ratio. Indeed, in this case, at the scale of the porous material, the local compliance writes :

$\mathbf{J}(t, x)=\mathbf{J}(0, x) f(t)$

where $f(t)$ is a scalar function of time $t$. The determination of the overall response of the cement paste as a function of porosity necessitates the resolution of a homogenization problem on the unit cell representing the porous material.

In the Laplace-Carson space Appendix B), the constitutive equation for this unit cell problem becomes :

$\mathbf{J}^{*}(p, x)=\mathbf{J}(0, x) f^{*}(p)$

Let $\varepsilon(x)$ be the elastic solution of the unit cell problem for prescribed overall strain $E$. Then, $\varepsilon(x)$ is also the solution of the unit problem with prescribed overall strain $E$ for all $p$ in the Laplace Carson space. Therefore :

$\mathbf{J}^{\text {hom }, *}(p)=\mathbf{J}^{\text {hom }}(0) f^{*}(p)$

Inverting the Laplace Carson transform gives:

$\mathbf{J}^{h o m}(t)=\mathbf{J}^{\text {hom }}(0) f(t)$

This demonstrates that if the cement paste is a two-phase porous material, the local compliance having a uniform in time Poisson's ratio, then the cement paste has a uniform in time Poisson's ratio and the effect of time and microstructure are uncoupled.

If the effect of changing the water to cement ratio were limited to a change of porosity in a two-phase porous material, the consequence on the viscoelastic behavior would be similar to the one described above. But it is known that the microstructure of the cement paste includes porosity, elastic unhydrated cement, elastic or viscoelastic products of hydration and other additives [53]. The higher the water to cement ratio is, the higher the hydration degree becomes [54] and the hydrated phases are assumed to be responsible for the viscoelastic behavior of cement paste [4]. Therefore, the assumption $\mathbf{C}_{k}=A_{k} \mathbf{C}_{0}\left(\frac{\alpha_{w}}{\rho_{c} \alpha_{c}}\right)$ probably underestimates the long term effect of an ITZ.

Numerical tests were performed on a $4 \mathrm{~mm}$ wide cubic cell depicting the microstructure of a mortar [Fig. 12]. At this scale, a voxel is approximately $10 \mu \mathrm{m}$ wide and the ITZ can be introduced. Various thickness $\delta$ between $0 \mu \mathrm{m}$ (no ITZ) and $50 \mu \mathrm{m}$ were tested. The larger the ITZ is, the lower the elastic and viscoelastic stiffnesses are. The relative decreases of identified viscoelastic 


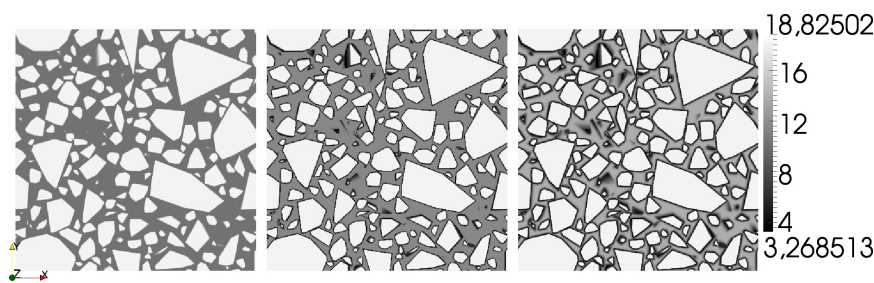

Lamé coefficient $\lambda(\mathrm{GPa})$ at elastic time step, $t-t_{0}=0$, for $\delta=0 \mu \mathrm{m}, 20 \mu \mathrm{m}$ and $50 \mu \mathrm{m}$.
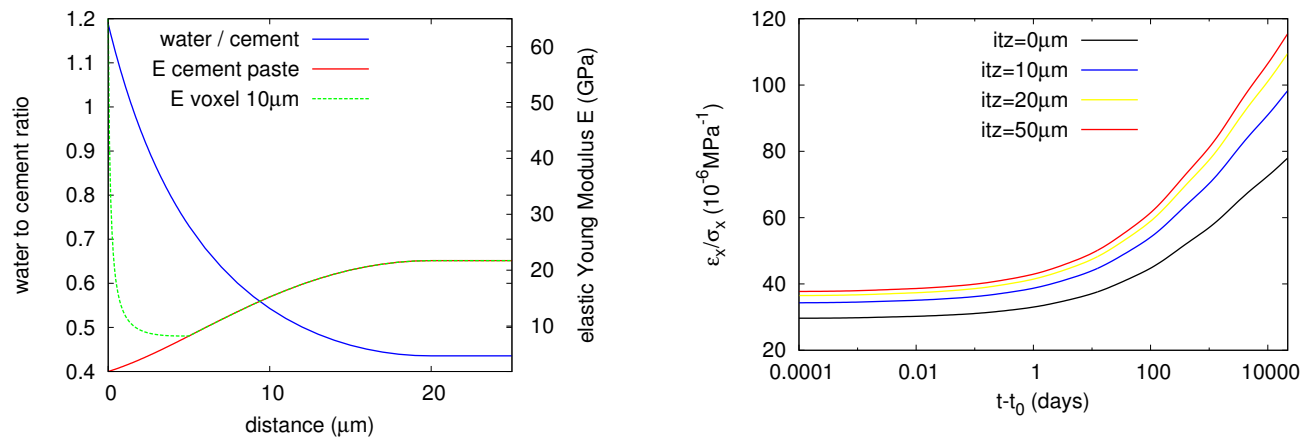

Figure 12: Top : an ITZ can be pictured on the microstructure of a mortar, depending on its thickness $\delta$. Bottom left : the local water to cement ratio is displayed as a function of the distance to the inclusion. The corresponding elastic Young modulus and the Young modulus of a $10 \mu \mathrm{m}$ voxel overlapping with inclusions are also displayed. Bottom right : the numerical solution to uniaxial creep test depends on the thickness of the ITZ. Both the elastic response and the the long term strain are modified by the introduction of an ITZ.

stiffnesses are twice larger than the one of the elastic stiffness [Tab. 4]. Moreover, according to the previous paragraph, it is likely that this effect is underestimated by our computations.

Therefore, the presence of an ITZ is a plausible explanation of discrepancies between creep strains of various concretes.

\section{Comparison of numerical and micromechanics methods}

\subsection{Semi-analytic methods}

\subsubsection{Linear viscoelastic homogenization}

Micromechanics methods remain practical to upscale the overall viscoelastic properties. In the frame of non-aging creep, the Laplace-Carson transform turns the time-depend problem into several elastic problems thanks to the correspondence principle [55, [56]. In this space, the Hashin-Shtrikman bounds [57], the Mori-Tanaka model [58, 59], the three-phase model of Christensen \& Lo[60] or the $n+1$-phase spherical model of Hervé \& Zaoui[61] deliver estimates of the macroscopic response. Coming back to the real space requires inverting the Laplace-Carson transform with numerical tools such as the Gaver-Stehfest algorithm [62, 63] or the collocation method [64, 65]. Semi-analytical elastic homog- 


\begin{tabular}{ccc|cc|cc} 
& $\begin{array}{c}\text { no ITZ } \\
\delta=0\end{array}$ & $\delta=20 \mu \mathrm{m}$ & & $\delta=50 \mu \mathrm{m}$ & \\
$\tau_{k}$ & $\begin{array}{c}\text { Young } \\
\text { Modulus of } \\
C_{k}\end{array}$ & $\begin{array}{c}\text { relative } \\
\text { difference } \\
\text { to no-itz } \\
\text { case }\end{array}$ & $\begin{array}{c}\text { Young } \\
\text { Modulus of }\end{array}$ & $\begin{array}{c}\text { relative } \\
\text { difference } \\
\text { to no-itz } \\
\text { case }\end{array}$ & $\begin{array}{c}\text { Young } \\
\text { Modulus of } \\
C_{k}\end{array}$ & $\begin{array}{c}\text { relative } \\
\text { difference } \\
\text { to no-itz } \\
\text { case }\end{array}$ \\
\hline 0 & 35 & 0 & 28.6 & -0.18 & 27.7 & -0.21 \\
20 & 181 & 0 & 123 & -0.32 & 116 & -0.36 \\
20000 & 41 & 0 & 26.7 & -0.35 & 25.3 & -0.39
\end{tabular}

Table 4: Effect of the ITZ on the identified macroscopic Young modulus of $\mathbf{C}_{k}$. The effect of the interface is more important on the long term creep behavior than on the elastic behavior as shown by the relative difference to the no-ITZ case.

enization models may also provide the time-dependent response through time stepping procedures [66, 67, 68. The analytic method combining the HashinShtrikman bound and the Laplace Carson transform is described in Appendix B.

\subsubsection{The tri-sphere model : a scalar parameter to account for the morphology of the microstructure}

Compared to the Hashin-Shtrikman model, the tri-sphere model of de Larrard \& Le Roy 69, 70] introduces an additional parameter $g^{*}$ to account for the morphology of the microstructure. The cementitious matrix is divided in two parts. A minimal part fills the gaps between the aggregates at maximum packing density $g^{*}$. The rest of the matrix ensures good rheological properties.

The corresponding homogenization procedure has two steps. First, the minimal part is merged with the inclusions using the upper Hashin-Shtrikman bound ( volume fraction $g^{*}$ ). Then, the rest of the matrix is introduced thank to a lower Hashin-Shtrikman bound [Fig. 13].

The close packing volume fraction $g^{*}$ arises from the compressible packing model of de Larrard [69], which extends the linear packing model of Stovall [71]. It depends on the close packing density $\Phi_{i}^{*}$ and volume fraction of solid material $y_{i}$ of each class $i$ of the sieve curve.

- For unimodal spherical inclusions, $g *=\Phi^{*}=\frac{\pi}{3 \sqrt{2}} \approx 0.74$

- For bimodal spherical inclusions and if there exists no interaction between the two classes :

$$
g^{*}=\min \left(\frac{\Phi^{*}}{1-y_{\text {small }}}, \frac{\Phi^{*}}{1-\left(1-\Phi^{*}\right)\left(1-y_{\text {small }}\right)}\right)
$$

At packing limits, if $y_{\text {small }}<0.21$, large inclusions dominate and small inclusions fill in the gaps. On the opposite, if $y_{\text {small }}>0.21$, large inclusions 


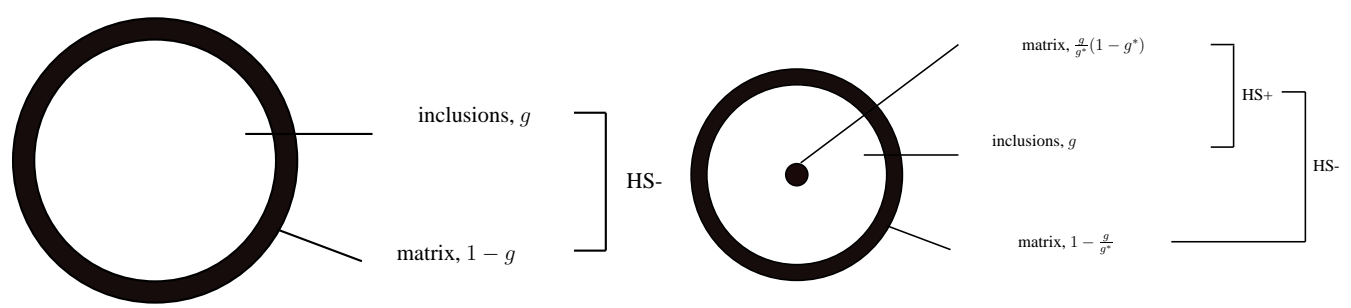

Figure 13: Homogenization schemes of the Hashin-Shtrikman model (left) and tri-sphere model (right).

are scarce and small inclusions are tightly packed. The bimodal distribution used in our numerical simulations has a volume fraction of solid material of small inclusions of $y_{\text {small }}=0.5$.

- A more precise knowledge of interactions between classes is required to address continuous inclusions' size distributions and irregular shapes. Typical values of $g^{*}$ for concretes are between $80 \%$ and $90 \%$.

\subsection{3. $n+1-$ phase spherical model to account for the Interfacial Transition Zone}

The $n+1$-phase spherical model of Hervé \& Zaoui [61][Fig. 16 extends the three-phase model of Christensen \& Lo 60]. It has been used by Nadeau [5] to upscale the elastic properties of mortars with an ITZ. The ITZ is depicted as successive layers of cement paste having different mechanical properties. This method is combined with the Laplace-Carson transform to estimate the time dependent strain of such a material.

In our case, the inputs are the same as in the numerical method : the distribution of the cement paste as a function of the distance to the nearest inclusion $f\left(d_{i}\right)$ is provided by the microstructure. The link between $d_{i}$, the water to cement ratio and the viscoelastic properties is described in section 1.2.8. Each layer has a width of $1 \mu \mathrm{m}$ and the corresponding volume fraction of the microstructure is estimated according to its discretized image. These volume fractions are then used as inputs for the $n+1$-phase spherical model in the Laplace Carson space.

The sieve curve and the shape of inclusions change the output of this micromechanics method since they affect the distribution of the cement paste as a function of the distance to the nearest inclusion $f\left(d_{i}\right)$ and the local volume fraction of cement $\alpha_{c}\left(d_{i}\right)$.

Outputs of these models are to be compared to full field numerical results.

\subsection{Comparison with numerical estimates}

\subsubsection{Influence of volume fraction}

Concrete microstructures made of crushed inclusions are built thank to the RSA algorithm. Three unit cells of each volume fraction of inclusions are built and 


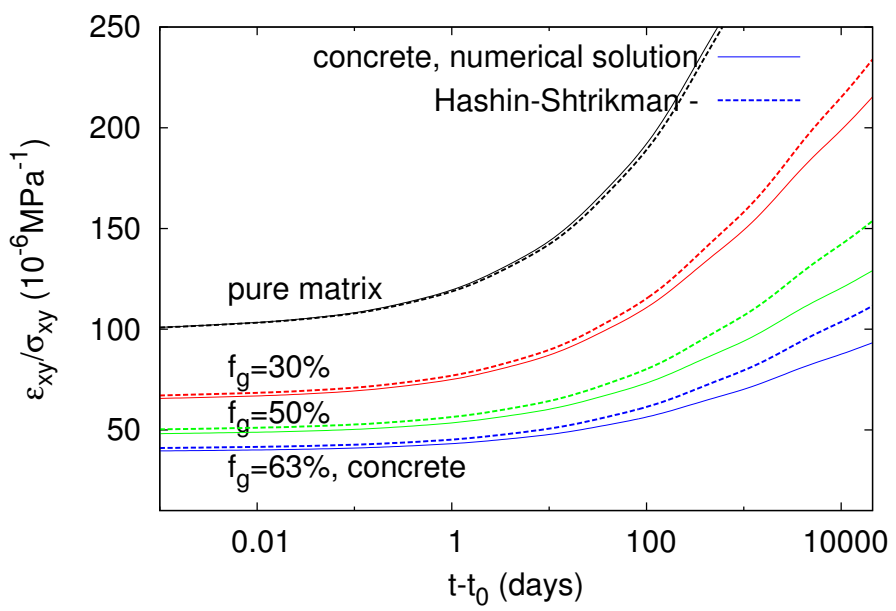

Figure 14: Viscoelastic responses to a shear loading for different volume fraction of inclusions. Results of crushed inclusions are close to the Hashin-Shtrikman bound in the Laplace Carson space.
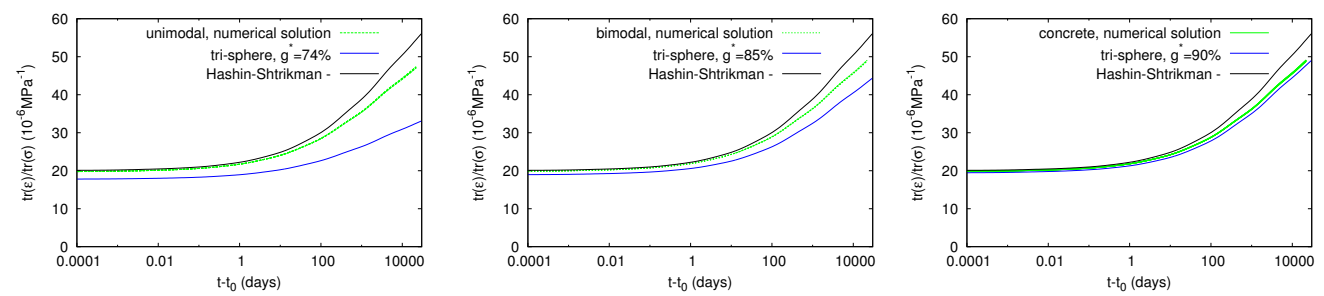

Figure 15: Results of the tri-sphere model 69, 70, for unimodal(left), bimodal(center) and concrete microstructures are compared to numerical estimates. The volume fraction of inclusions is $63 \%$.

discretized on $384^{3}$ grids [Fig. 4] to run viscoelastic computations. A numerical shear creep test is performed on these unit cells. The overall strains is close the one estimated by the Hashin-Shtrikman bound in the Laplace-Carson space [Fig. 14] at different volume fractions of inclusions.

The volume fraction of inclusions being set to $63 \%$, a small deviation from the Hashin-Shtrikman bound in the Laplace-Carson space occurs at long term [Fig. 9. The heterogeneity between the inclusions and the matrix may explain this feature. On the first time step, the elastic loading, the inclusions are 5 times stiffer than the matrix. On the last time step, 60 years after loading, the tangent behavior of the inclusions is 14 times stiffer than the one of the matrix. 


\subsubsection{Hashin-Shtrikman, tri-sphere model and numerical estimates}

The creep strains estimated by the tri-sphere model are close to our numerical results for the bimodal and concrete microstructures. As $g^{*}$ is large, this model delivers estimates close to the Hashin-Shtrikman ones. But estimated time-dependent strains are different for the unimodal microstructure. Though the tri-sphere model anticipates a lower creep strain due to $g^{*}=0.74$, the numerical results for unimodal microstructures remain close to the other ones [Fig. 15. Since concrete materials exhibit large $g^{*}$, the three methods are relevant to produce estimates of the overall macroscopic strain.

\subsubsection{Interfacial Transition Zone : $n+1$ phase spherical model and numerical estimates}

Numerical uniaxial creep tests are performed on the mortar with ITZ defined in section 1.2 .8 on page 21 . There is a difference between the estimated overall strain estimated by the numerical method and the one produced by the $n+1$ phase spherical model : the later seems to slightly underestimate the effect of the ITZ [Fig. 16].

Inputs are similar up to the mechanical computations. Therefore, representing the ITZ as successive layers of coating around the inclusions is not precise for this mortar. At this scale, with this volume fraction of inclusions $(50 \%)$ and the given sieve curve, a $10 \mu \mathrm{m}$-wide ITZ is a percolated phase. Moreover, stress concentrations occur between close inclusions, that is in the ITZ. It could explain why the effect of the ITZ is larger than expected by the semi-analytical model.

A two-scale homogenization method was defined by merging the layers of the ITZ and the matrix first according to the Reuss bound. Then, the inclusions are introduced through a lower Hashin-Shtrikman bound. Even if this crude method performs slightly better than the $n+1$-phase spherical model on this mortar, it still underestimates the time dependent strain. The fact that the numerical estimates are softer than the response of this crude model is a clue than the scale of the ITZ and the scale of the inclusions cannot be separated.

\subsection{Discussions}

There are several assumptions to question :

- Are the inclusions perfectly bonded to the matrix ?

- Is viscoelasticity the right frame to model the basic creep of concrete ?

The long-term discrepancies between these two concretes [Tab. 1] may also be partly due to the chemical reaction between calcium carbonate $\mathrm{CaCO}_{3}$ from the limestone filler at Paluel and tricalciium aluminate $\mathrm{C}_{3} \mathrm{~A}$ from the clinker. For the concrete of Paluel, using the model defined by de Larrard [69, the long term 

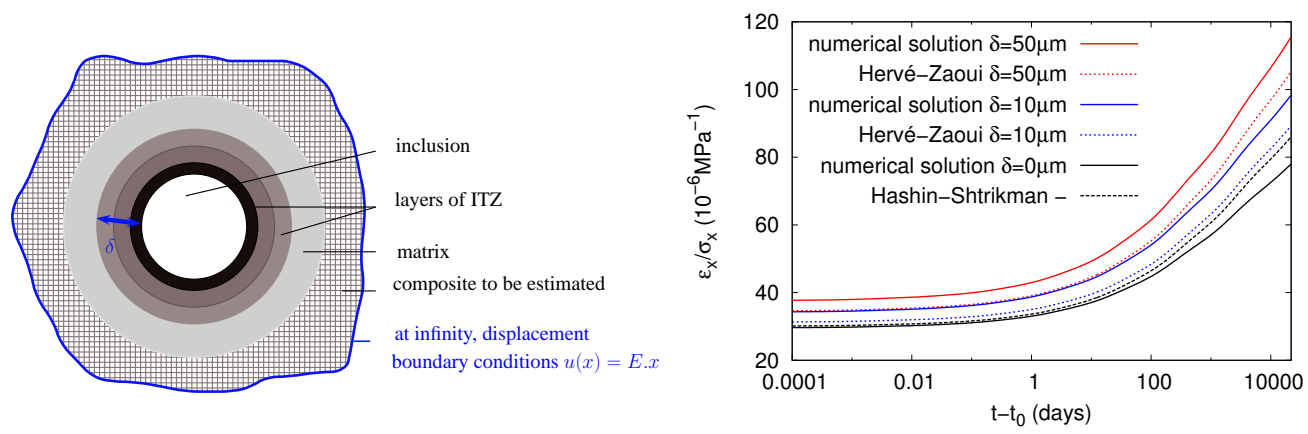

Figure 16: Results of the $n+1$ phase spherical model (left) 61 for a mortar is compared to numerical estimates for different thickness of ITZ $\delta$. The $n+1$ phase spherical model underestimates the time dependent strain in case of a creep test (right).

effect of the additional binder on compressive strength is comparable to $30 \mathrm{~kg} / \mathrm{m}^{3}$ of cement par cubic meter of concrete.

It is well known that the time dependent behavior of concrete goes beyond viscoelasticity. The time-depend strain may be separated in different components : endogenous shrinkage, drying shrinkage, basic creep and drying creep. This divide-and-conquer strategy is the frame of EU standards Eurocode 2 and models of Granger [1, Benboudjema [72], de Larrard [69] and B3 model of Bažant [73] among others. It eases the introduction of moisture content, structural effects and temperature effects. Rossi pledges instead for a unified strategy in which basic creep is a self-drying shrinkage under stress [74]. The assumption is that the creation of microcracks during a creep step (constant load level imposed during the creep test) generates water transfers which induces some additional self-drying shrinkage. This model is consistent with records of acoustic emissions during compressive creep tests [75].

The basic creep of concrete is an ageing phenomenon and the current numerical model could be improved by considering ageing linear viscoelasticity. Moreover, additional eigenstrains due to shrinkage (autogeneous or drying) could be introduced, in order to better estimate the local stresses in the matrix and assess the possible occurrence of damage. The introduction of microcracking, or damage, would also help to explain non-linear creep above $\approx 40 \%$ of compressive strength. In [74, stress levels are above $\approx 50 \%$ of compressive strength whereas the overall biaxial prestress of containment buildings is below $30 \%$ of compressive strength in each direction $\left(\sigma_{\theta \theta} \approx 12 M P a\right.$ and $\left.\sigma_{z z} \approx 8 M P a\right)$. 


\section{Conclusion}

Methods to build various artificial microstructures have been defined and a numerical frame to study the viscoelastic behavior of concrete as a matrixinclusion material is presented. Numerical results do not differ largely from the Hashin-Shtrikman estimates as long as volume fractions remain below $63 \%$ and the aspect ratio of inclusions and the contrast between phases remain low. Either the sieve curve and the inclusion shape do not influence creep or the matrixinclusion model is too simple to be accurate. Since concretes with close volume fraction of aggregates exhibit very different long term creep, considering such concretes as a two-phase matrix-inclusion materials to study creep is questionable. A heterogeneous cementitious matrix, interfacial zones or decohesion phenomena might explain such differences.

3D numerical simulations may be performed to assess the correctness of micromechanics models. For instance, it has been shown that numerical estimates of creep strains are different from the one obtained by the micromechanics $n+1$ phase spherical model for modeling the Interfacial Transition Zone in a mortar. The $n+1$ phase spherical model assumes that the ITZ is an isolated layer of around each inclusion whereas the numerical model accounts for the ITZ being a percolated phase in the mortar.

The gains of 3D numerical simulation are the ability to handle aging behaviors and, to a certain extent, the access to the magnitude of stress concentrations. Large scale computations are required to study concrete or other heterogeneous materials with a large representative volume element, especially if a non-linear phenomenon is introduced at the local scale.

\section{Appendix A. FFT solvers}

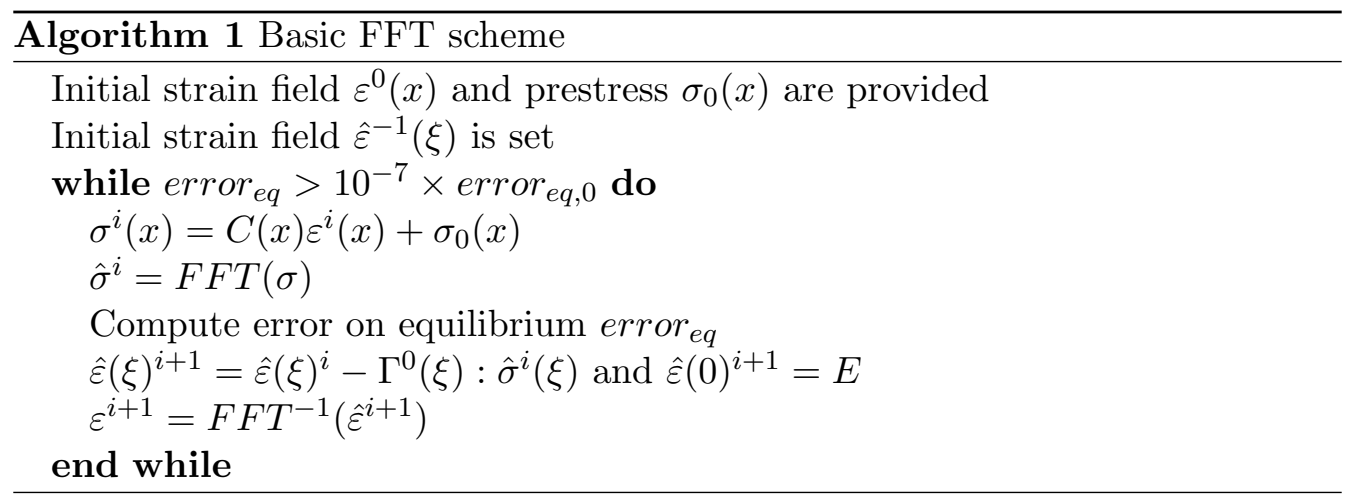




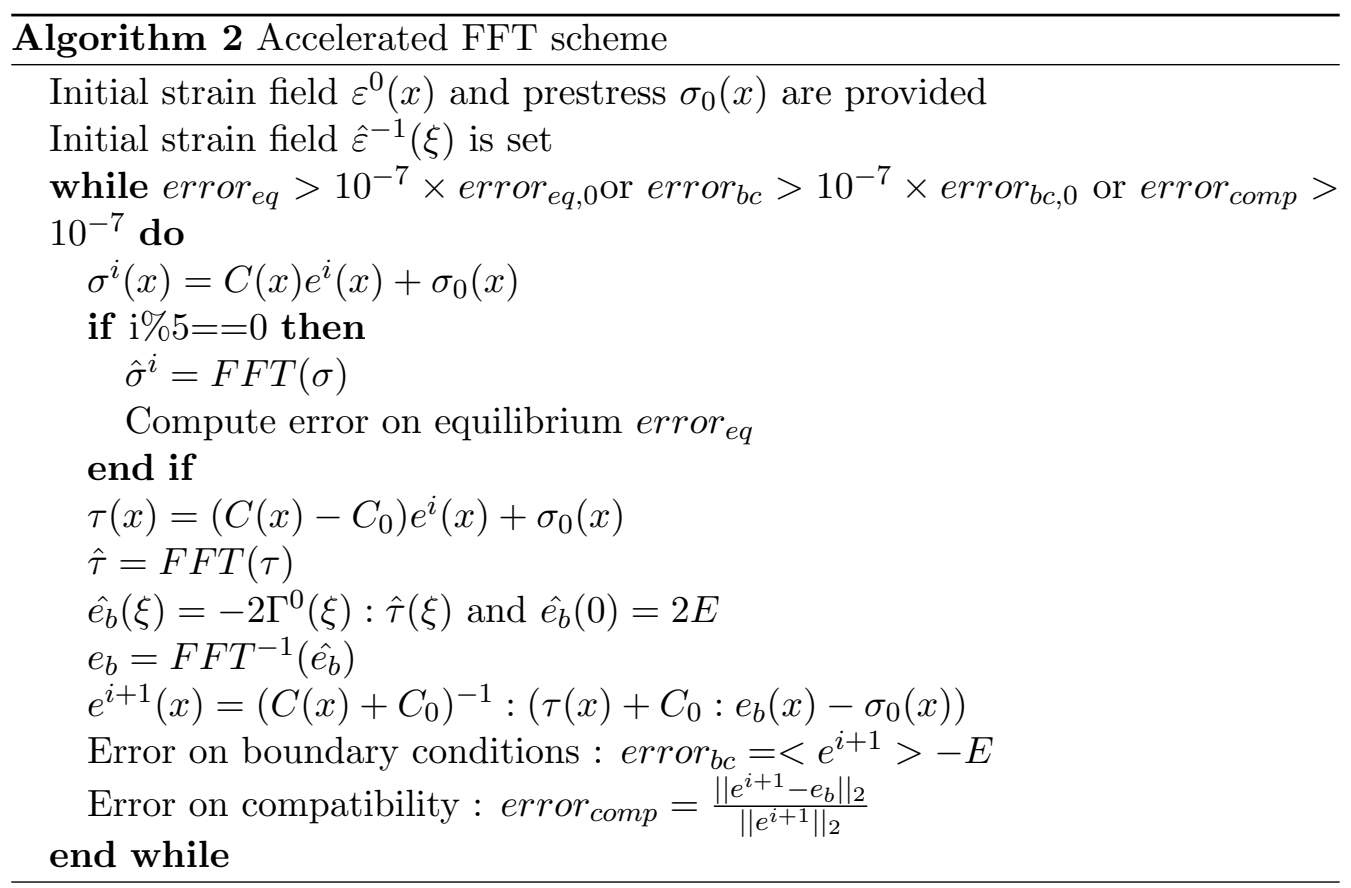

\section{Appendix B. Hashin-Shtrikman bound and Laplace-Carson transform}

Appendix B.1. The correspondence principle

The non-aging linear viscoelastic problem corresponds to elastic problems thank to the Laplace-Carson transform. The transform of a function $g(t)$ is $\hat{g}(p)=$ $p \int_{0}^{\infty} g(t) e^{-p t} d t$. The transform of its derivative $\dot{g}(t)$ is $\hat{\dot{g}}(p)=p \hat{g}(p)-p . g(0)$.

In our case, elastic inclusions (volume fraction $f_{i}$ ) are embedded in a viscoelastic matrix modeled by a single Kelvin chain. The relaxation problem reads

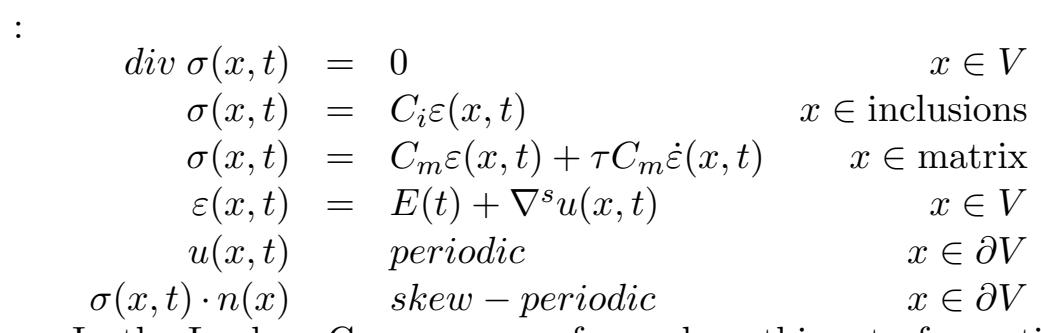

In the Laplace-Carson space, for each $p$, this set of equation corresponds to the elastic problem : 


$$
\begin{aligned}
& \operatorname{div}(\hat{\sigma}(x, p))=0 \\
& \hat{\sigma}(x, p)=C_{i} \hat{\varepsilon}(p) \\
& x \in V \\
& \hat{\sigma}(p)=(1+p \tau) C_{m} \hat{\varepsilon}(x, p) \quad x \in \text { matrix } \\
& \hat{\varepsilon}(x, p)=E(p)+\nabla^{s} \hat{u}(x, p) \quad x \in V \\
& \hat{u}(x, p) \quad \text { periodic } \quad x \in \partial V \\
& \hat{\sigma}(x, p) \cdot n(x) \quad \text { skew-periodic } \quad x \in \partial V
\end{aligned}
$$

The Hashin-Shtrikman bound is an analytical model which provides estimates of the macroscopic response of the elastic material.

$$
\begin{aligned}
& <\hat{\sigma}(p)>=\hat{C_{H S}}(p)<\hat{\varepsilon}(p)>=\hat{C_{H}}(p) E \\
& C_{\hat{H} S-}(p) \text { is isotropic and its bulk modulus and shear modulus are : } \\
& K_{m}(p)=(1+p \tau) K_{m}, \mu_{m}(p)=(1+p \tau) \mu_{m} \\
& K_{H S-}(p)=K_{m}(p)+\frac{f_{i}}{\frac{1}{K_{i}-K_{m}(p)}+\frac{3\left(1-f_{i}\right)}{3 K_{m}(p)+4 \mu_{m}(p)}} \\
& \mu_{H S-}(p)=\mu_{m}(p)+\frac{f_{i}}{\frac{1}{\mu_{i}-\mu_{m}(p)}+\frac{6\left(K_{m}(p)+2 \mu_{m}(p)\right)\left(1-f_{i}\right)}{5 \mu_{m}(p)\left(3 K_{m}(p)+4 \mu_{m}(p)\right)}}
\end{aligned}
$$

The Laplace-Carson transform of the macroscopic stress $\langle\hat{\sigma}\rangle(p)$ is computed and the last stage is inverting this transform.

\section{Appendix B.2. Inverting the Laplace-Carson transform}

Lots of methods are available to invert the Laplace-Carson transform. In this study, the Gaver-Stehfest formula [62 has been used :

$$
\begin{aligned}
& g(t, M)=\sum_{k=1}^{2 M} \frac{\xi_{k}}{k} \hat{g}\left(\frac{k \ln (2)}{t}\right) \\
& \text { and } \xi_{k}=(-1)^{M+k} \sum_{j=E\left(\frac{k+1}{2}\right)}^{\min (k, M)} \frac{j^{M+1}}{M !}\left(\begin{array}{c}
M \\
j
\end{array}\right)\left(\begin{array}{c}
2 j \\
j
\end{array}\right)\left(\begin{array}{c}
j \\
k-j
\end{array}\right)
\end{aligned}
$$

Computing the binomial coefficients requires high precision and the long double type (IEEE 754, decimal on 128 bits) provided it. If $M$ is too low, the formula lacks precision [63. If $M$ is too high, small errors on $\hat{g}\left(\frac{k \ln (2)}{t}\right)$ may trigger large errors on the outcome. $M$ is set to 7 .

Therefore, to estimate the response at time $t$, about 14 elastic computations are required. This formula does not seem to be practical for FEM since it lacks stability or precision. It is suitable as long as the numerical error in the Laplace-Carson space remains very low. This algorithm is useful when the Hashin-Shtrikman analytical formula or self-consistent estimate are computed in the Laplace-Carson space.

[1] L. Granger, Comportement différé du béton dans les enceintes de centrales nucléaires : analyse et modélisation, Ph.D. thesis, Ecole Nationale des Ponts et Chaussées (1995).

[2] J. Escoda, F. Willot, D. Jeulin, J. Sanahuja, C. Toulemonde, Estimation of local stresses and elastic properties of a mortar sample by $\{\mathrm{FFT}\}$ computation of fields on a $3 \mathrm{~d}$ image, 
Cement and Concrete Research 41 (5) (2011) 542 - 556. doi:http://dx.doi.org/10. 1016/j.cemconres.2011.02.003.

URL http://www.sciencedirect.com/science/article/pii/S0008884611000408

[3] F. Bignonnet, K. Sab, L. Dormieux, S. Brisard, A. Bisson, Macroscopically consistent non-local modeling of heterogeneous media Computer Methods in Applied Mechanics and Engineering 278 (0) (2014) 218 - 238. doi:http://dx.doi.org/10.1016/j.cma.2014.05. 014.

URL http://www.sciencedirect.com/science/article/pii/S0045782514001753

[4] V. Šmilauer, Z. P. Bažant, Identification of viscoelastic c-s-h behavior in mature cement paste by fft-based homogenization method, Cement and Concrete Research 40 (2) (2010) 197 - 207. doi:10.1016/j.cemconres.2009.10.003 URL http://www.sciencedirect.com/science/article/pii/S0008884609002865

[5] J. Nadeau, A multiscale model for effective moduli of concrete incorporating \{ITZ\} water-cement ratio gradients, aggregate size distributions, and entrapped voids, Cement and Concrete Research 33 (1) (2003) 103 - 113. doi:http://dx.doi.org/10.1016/ S0008-8846(02) 00931-6

URL http://www.sciencedirect.com/science/article/pii/S0008884602009316

[6] J. Feder, Random sequential adsorption, Journal of Theoretical Biology 87 (2) (1980) 237 - 254. doi:http://dx.doi.org/10.1016/0022-5193(80)90358-6

URL http://www.sciencedirect.com/science/article/pii/0022519380903586

[7] B. D. Lubachevsky, F. H. Stillinger, Geometric properties of random disk packings, Journal of Statistical Physics 60 (1990) 561-583.

[8] C. B. Barber, D. P. Dobkin, H. Huhdanpaa, The quickhull algorithm for convex hulls, ACM Transactions on Mathematical Software 22 (4) (1996) 469-483.

[9] Qhull software, http://www.qhull.org accessed: 2013-06-28.

[10] D. Bentz, E. J. Garboczi, K. A. Snyder, A hard core/soft shell microstructural model for studying percolation and transport in three-dimensional composite media, Tech. rep., National Institute of Standards and Technology (1999).

[11] J. Escoda, Modélisation morphologique et micromécanique 3d de matériaux cimentaires, Ph.D. thesis, Mines Paristech (2012).

[12] E. Gilbert, D. Johnson, S. Keerthi, A fast procedure for computing the distance between complex objects in three space, in: Robotics and Automation. Proceedings. 1987 IEEE International Conference on, Vol. 4, 1987, pp. 1883-1889. doi:10.1109/ROBOT.1987.1087825

[13] Bullet physics library, http://www. bulletphysics.org, accessed: 2013-08-07.

[14] A. R. Kansal, S. Torquato, F. H. Stillinger, Computer generation of dense polydisperse sphere packings, The Journal of Chemical Physics 117 (18) (2002) 8212-8218. doi:10. 1063/1.1511510. URL http://link.aip.org/link/?JCP/117/8212/1

[15] A. Donev, S. Torquato, F. H. Stillinger, Neighbor list collision-driven molecular dynamics simulation for nonspherical hard particles. i. algorithmic details, Journal of Computational Physics 202 (2) (2005) 737 - 764. doi:http://dx.doi.org/10.1016/j.jcp.2004.08.014 URL http://www . sciencedirect.com/science/article/pii/S0021999104003146

[16] A. Donev, S. Torquato, F. H. Stillinger, Neighbor list collision-driven molecular dynamics simulation for nonspherical hard particles.: Ii. applications to ellipses and ellipsoids Journal of Computational Physics 202 (2) (2005) 765 - 793. doi:http://dx.doi.org/10.1016/j. jcp.2004.08.025

URL http://www.sciencedirect.com/science/article/pii/S0021999104003948

[17] E. Ghossein, M. Lévesque, A fully automated numerical tool for a comprehensive validation of homogenization models and its application to spherical particles reinforced composites, International Journal of Solids and Structures 49 (11-12) (2012) 1387-1398.

[18] O. Zienkiewicz, M. Watson, I. King, A numerical method of visco-elastic stress analysis 
International Journal of Mechanical Sciences 10 (10) (1968) 807 - 827. doi:10.1016/ 0020-7403(68)90022-2

URL http://wWw.sciencedirect.com/science/article/pii/0020740368900222

[19] R. L. Taylor, K. S. Pister, G. L. Goudreau, Thermomechanical analysis of viscoelastic solids, International Journal for Numerical Methods in Engineering 2 (1) (1970) 45-59. doi:10.1002/nme.1620020106.

URL http://dx.doi.org/10.1002/nme.1620020106

[20] Z. P. Bažant, S. T. Wu, Creep and shrinkage law for concrete at variable humidity, Journal of the Engineering Mechanics Division 100 (6) (1974) 1183-1209.

[21] P. Suquet, H. Moulinec, O. Castelnau, M. Montagnat, N. Lahellec, F. Grennerat, P. Duval, R. Brenner, Multi-scale modeling of the mechanical behavior of polycrystalline ice under transient creep Procedia \{IUTAM 3 (0) (2012) 76 - 90, iUTAM Symposium on Linking Scales in Computations: From Microstructure to Macro-scale Properties. doi:http://dx. doi.org/10.1016/j.piutam.2012.03.006

URL http://www.sciencedirect.com/science/article/pii/S2210983812000077

[22] H. Moulinec, P. Suquet, A numerical method for computing the overall response of nonlinear composites with complex microstructure, Computer Methods in Applied Mechanics and Engineering 157 (1-2) (1998) 69 - 94. doi:http://dx.doi.org/10.1016/S0045-7825(97) 00218-1.

URL http://www.sciencedirect.com/science/article/pii/S0045782597002181

[23] M. Idiart, H. Moulinec, P. P. Castañeda, P. Suquet, Macroscopic behavior and field fluctuations in viscoplastic composites: Second-order estimates versus full-field simulations, Journal of the Mechanics and Physics of Solids 54 (5) (2006) 1029 - 1063. doi:10.1016/j.jmps.2005.11.004

URL http://www.sciencedirect.com/science/article/pii/S0022509605002188

[24] D. J. Eyre, G. W. Milton, A fast numerical scheme for computing the response of composites using grid refinement, The European Physical Journal Applied Physics 6 (1999) 41-47. doi:10.1051/epjap: 1999150

URL http://www.epjap.org/article_S1286004299001500

[25] H. Moulinec, F. Silva, Comparison of three accelerated FFT-based schemes for computing the mechanical response of composite materials, International Journal for Numerical Methods in Engineering (2013) soumis.

URL http://hal . archives-ouvertes .fr/hal-00787089

[26] Fastest fourier transform in the west, http://www.fftw.org, accessed: 2013-08-07.

[27] M. Frigo, S. G. Johnson, The design and implementation of FFTW3, Proceedings of the IEEE 93 (2) (2005) 216-231, special issue on "Program Generation, Optimization, and Platform Adaptation".

[28] S. Balay, J. Brown, K. Buschelman, W. D. Gropp, D. Kaushik, M. G. Knepley, L. C. McInnes, B. F. Smith, H. Zhang, PETSc Web page, http://www.mcs.anl.gov/petsc (2013).

[29] S. Balay, J. Brown, , K. Buschelman, V. Eijkhout, W. D. Gropp, D. Kaushik, M. G. Knepley, L. C. McInnes, B. F. Smith, H. Zhang, PETSc users manual, Tech. Rep. ANL95/11 - Revision 3.4, Argonne National Laboratory (2013).

[30] S. Balay, W. D. Gropp, L. C. McInnes, B. F. Smith, Efficient management of parallelism in object oriented numerical software libraries, in: E. Arge, A. M. Bruaset, H. P. Langtangen (Eds.), Modern Software Tools in Scientific Computing, Birkhäuser Press, 1997, pp. 163202.

[31] A. Kwan, C. Mora, H. Chan, Particle shape analysis of coarse aggregate using digital image processing, Cement and Concrete Research 29 (9) (1999) 1403 - 1410. doi:http: //dx.doi.org/10.1016/S0008-8846(99)00105-2.

URL http://www.sciencedirect.com/science/article/pii/S0008884699001052 
[32] ASTM, Standard practice for description and identification of soils (visual-manual procedure), Tech. Rep. ASTM Standard D2488-09a, ASTM (2009). doi:10.1520/D2488-09A

[33] AFNOR, Essais pour déterminer les caractéristiques géométriques des granulats - partie 3 : détermination de la forme des granulats - coefficient d'aplatissement, Tech. Rep. NF EN 933-3, AFNOR (2012).

[34] J. Hu, P. Stroeven, Shape characterization of concrete aggregate Image Analysis \& Stereology 25 (1) (2011) 43-53. URL http://www.ias-iss.org/ojs/IAS/article/view/791

[35] M. Gambhir, Concrete Technology: Theory and Practice, Mc Graw Hill Education, 2013.

[36] S. Brisard, L. Dormieux, Fft-based methods for the mechanics of composites: A general variational framework, Computational Materials Science 49 (3) (2010) 663 - 671. doi: http://dx.doi.org/10.1016/j.commatsci.2010.06.009. URL http://www.sciencedirect.com/science/article/pii/S0927025610003563

[37] C. F. Dunant, B. Bary, A. B. Giorla, C. Péniguel, J. Sanahuja, C. Toulemonde, A.-B. Tran, F. Willot, J. Yvonnet, A critical comparison of several numerical methods for computing effective properties of highly heterogeneous materials, Advances in Engineering Software 58 (0) (2013) 1 - 12. doi:http://dx.doi.org/10.1016/j.advengsoft.2012.12.002 URL http://www.sciencedirect.com/science/article/pii/S0965997812001846

[38] K. Sab, On the homogenization and the simulation of random materials, European Journal of Mechanics A-Solids 11 (5) (1992) 585-607.

[39] T. Kanit, S. Forest, I. Galliet, V. Mounoury, D. Jeulin, Determination of the size of the representative volume element for random composites: statistical and numerical approach International Journal of Solids and Structures 40 (13-14) (2003) 3647 - 3679. doi :http: //dx.doi.org/10.1016/S0020-7683(03)00143-4.

URL http://www.sciencedirect.com/science/article/pii/S0020768303001434

[40] A. A. Gusev, Representative volume element size for elastic composites: A numerical study Journal of the Mechanics and Physics of Solids 45 (9) (1997) 1449 - 1459. doi:http: //dx.doi.org/10.1016/S0022-5096(97)00016-1.

URL http://www.sciencedirect.com/science/article/pii/S0022509697000161

[41] K. Sab, B. Nedjar, Periodization of random media and representative volume element size for linear composites Comptes Rendus Mécanique 333 (2) (2005) 187 - 195. doi:http: //dx.doi.org/10.1016/j.crme.2004.10.003

URL http://www.sciencedirect.com/science/article/pii/S1631072104002256

[42] E. Gal, R. Kryvoruk, Meso-scale analysis of \{FRC $\}$ using a two-step homogenization approach Computers \& Structures 89 (11-12) (2011) 921-929, computational Fluid and Solid Mechanics 2011 Proceedings Sixth MIT Conference on Computational Fluid and Solid Mechanics. doi:http://dx.doi.org/10.1016/j.compstruc.2011.02.006 URL http://www.sciencedirect.com/science/article/pii/S0045794911000393

[43] M. Ostoja-Starzewski, Material spatial randomness: From statistical to representative volume element, Probabilistic Engineering Mechanics 21 (2) (2006) 112 - 132. doi:http: //dx.doi.org/10.1016/j.probengmech.2005.07.007

URL http://www.sciencedirect.com/science/article/pii/S0266892005000433

[44] A. Lachihab, K. Sab, Aggregate composites: a contact based modeling, Computational Materials Science 33 (4) (2005) 467 -490. doi : http://dx.doi.org/10.1016/j.commatsci . 2004.10 .003

URL http://www.sciencedirect.com/science/article/pii/S0927025604002642

[45] K. L. Scrivener, A. K. Crumbie, P. Laugesen, The interfacial transition zone (itz) between cement paste and aggregate in concrete, Interface Science 12 (2004) 411-421, 10.1023/B:INTS.0000042339.92990.4c. URL http://dx.doi.org/10.1023/B:INTS.0000042339.92990.4c

[46] S. Diamond, J. Huang, The $\{$ ITZ $\}$ in concrete - a different view based on image analysis 33 
and \{SEM\} observations, Cement and Concrete Composites 23 (2-3) (2001) $179-188$, special Theme Issue on Image Analysis. doi:http://dx.doi.org/10.1016/S0958-9465(00) 00065-2.

URL http://www.sciencedirect.com/science/article/pii/S0958946500000652

[47] A. Hussin, C. Poole, Petrography evidence of the interfacial transition zone (itz) in the normal strength concrete containing granitic and limestone aggregates, Construction and Building Materials 25 (5) (2011) 2298 - 2303. doi:http://dx.doi.org/10.1016/j. conbuildmat.2010.11.023.

URL http://www.sciencedirect.com/science/article/pii/S0950061810005519

[48] C. Neubauer, H. Jennings, E. Garboczi, A three-phase model of the elastic and shrinkage properties of mortar, Advanced Cement Based Materials 4 (1) (1996) 6-20. doi:http: //dx.doi.org/10.1016/S1065-7355(96)90058-9.

URL http://www.sciencedirect.com/science/article/pii/S1065735596900589

[49] E. Garboczi, J. Berryman, Elastic moduli of a material containing composite inclusions: effective medium theory and finite element computations, Mechanics of Materials 33 (8) (2001) 455 - 470. doi:http://dx.doi.org/10.1016/S0167-6636(01)00067-9

URL http://www.sciencedirect.com/science/article/pii/S0167663601000679

[50] F. Grondin, M. Matallah, How to consider the interfacial transition zones in the finite element modelling of concrete?, Cement and Concrete Research 58 (0) (2014) $67-75$. doi:http://dx.doi.org/10.1016/j.cemconres.2014.01.009.

URL http://www.sciencedirect.com/science/article/pii/S0008884614000106

[51] M. Vandamme, F.-J. Ulm, Nanoindentation investigation of creep properties of calcium silicate hydrates, Cement and Concrete Research 52 (0) (2013) $38-52$. doi:http://dx. doi.org/10.1016/j.cemconres.2013.05.006

URL http://www.sciencedirect.com/science/article/pii/S0008884613001191

[52] J. Nadeau, Water-cement ratio gradients in mortars and corresponding effective elastic properties, Cement and Concrete Research 32 (3) (2002) 481 - 490. doi:http://dx.doi. org/10.1016/S0008-8846(01)00710-4

URL http://www.sciencedirect.com/science/article/pii/S0008884601007104

[53] S. Diamond, The microstructure of cement paste and concrete - a visual primer, Cement and Concrete Composites 26 (8) (2004) 919 - 933, scanning electron microscopy of cements and concretes. doi:http://dx.doi.org/10.1016/j.cemconcomp.2004.02.028. URL http://www.sciencedirect.com/science/article/pii/S0958946504000447

[54] R. A. Cook, K. C. Hover, Mercury porosimetry of hardened cement pastes, Cement and Concrete Research 29 (6) (1999) 933 - 943. doi:http://dx.doi.org/10.1016/ S0008-8846(99) 00083-6.

URL http://www.sciencedirect.com/science/article/pii/S0008884699000836

[55] E. Lee, Stress analysis for linear viscoelastic materials, Rheologica Acta 1 (4-6) (1961) 426-430. doi:10.1007/BF01989085. URL http://dx.doi.org/10.1007/BF01989085

[56] J. Mandel, Cours de mécanique des milieux continus, Gauthier-Villars, 1966.

[57] Z. Hashin, S. Shtrikman, A variational approach to the theory of the elastic behaviour of multiphase materials, Journal of the Mechanics and Physics of Solids 11 (2) (1963) 127 140. doi:10.1016/0022-5096(63)90060-7.

URL http://www.sciencedirect.com/science/article/pii/0022509663900607

[58] T. Mori, K. Tanaka, Average stress in matrix and average elastic energy of materials with misfitting inclusions, Acta Metallurgica 21 (5) (1973) 571 - 574. doi:10.1016/ 0001-6160(73) 90064-3

URL http://www.sciencedirect.com/science/article/pii/0001616073900643

[59] F. Fisher, L. Brinson, Viscoelastic interphases in polymer-matrix composites: theoretical models and finite-element analysis, Composites Science and Technology 61 (5) (2001) 731 
- 748. doi:10.1016/S0266-3538(01)00002-1.

URL http://www.sciencedirect.com/science/article/pii/S0266353801000021

[60] R. Christensen, K. Lo, Solutions for effective shear properties in three phase sphere and cylinder models, Journal of the Mechanics and Physics of Solids 27 (4) (1979) $315-330$. doi:10.1016/0022-5096(79)90032-2

URL http://www.sciencedirect.com/science/article/pii/0022509679900322

[61] E. Herve, A. Zaoui, n-layered inclusion-based micromechanical modelling, International Journal of Engineering Science 31 (1) (1993) 1 - 10. doi:http://dx.doi.org/10.1016/ 0020-7225(93) 90059-4

URL http://www.sciencedirect.com/science/article/pii/0020722593900594

[62] H. Stehfest, Algorithm 368: Numerical inversion of laplace transforms [d5], Commun. ACM 13 (1) (1970) 47-49. doi:10.1145/361953.361969

URL http://doi . acm .org/10.1145/361953.361969

[63] W. Whitt, A unified framework for numerically inverting laplace transforms, INFORMS Journal on Computing 18 (2006) 408-421.

[64] R. Schapery, Approximate methods of transform inversion for viscoelastic stress analysis, in: fourth U.S. National Congress of Applied Mechanics, 1962, pp. 1075-1085.

[65] M. Lévesque, M. Gilchrist, N. Bouleau, K. Derrien, D. Baptiste, Numerical inversion of the Laplace-Carson transform applied to homogenization of randomly reinforced linear viscoelastic media, Computational Mechanics 40 (4) (2007) 771-789. doi:10.1007/ s00466-006-0138-6.

URL http://dx.doi.org/10.1007/s00466-006-0138-6

[66] N. Lahellec, P. Suquet, Effective behavior of linear viscoelastic composites: A timeintegration approach, International Journal of Solids and Structures 44 (2) (2007) 507 - 529. doi:http://dx.doi.org/10.1016/j.ijsolstr.2006.04.038

URL http://www.sciencedirect.com/science/article/pii/S002076830600148X

[67] Q. H. Vu, R. Brenner, O. Castelnau, H. Moulinec, P. Suquet, A self-consistent estimate for linear viscoelastic polycrystals with internal variables inferred from the collocation method, Modelling and Simulation in Materials Science and Engineering 20 (2) (2012) 024003. URL http://stacks . iop.org/0965-0393/20/i=2/a=024003

[68] J. Sanahuja, Effective behaviour of ageing linear viscoelastic composites: Homogenization approach, International Journal of Solids and Structures 50 (19) (2013) 2846 - 2856. doi: http://dx.doi.org/10.1016/j.ijsolstr.2013.04.023

URL http://www.sciencedirect.com/science/article/pii/S0020768313001807

[69] F. de Larrard, Structures granulaires et formulation des bétons - Concrete Mixture - Proportionning - A scientific approach, no. 9, Modern technology Series, E \& FN SPON, Londres, 1999.

[70] R. L. Roy, Déformations instantanées et différées des bétons à hautes performances, Ph.D. thesis, Ecole Nationale des Ponts et Chaussées (1995).

[71] T. Stovall, F. de Larrard, M. Buil, Linear packing density model of grain mixtures, Powder Technology 48 (1) (1986) 1 - 12. doi:http://dx.doi.org/10.1016/0032-5910(86) 80058-4.

URL http://www.sciencedirect.com/science/article/pii/0032591086800584

[72] F. Benboudjema, Modelisation des déformations différées du béton sous sollicitation biaxiales. application aux enceintes de confinement de batiments réacteurs des centrales nucléaires, Ph.D. thesis, Université de Marne la Vallée (2011).

[73] Creep and shrinkage prediction model for analysis and design of concrete structuresmodel b3 , Materials and Structures 28 (6) (1995) 357-365. doi:10.1007/BF02473152 URL http://dx.doi.org/10.1007/BF02473152

[74] P. Rossi, J.-L. Tailhan, F. L. Maou, L. Gaillet, E. Martin, Basic creep behavior of concretes investigation of the physical mechanisms by using acoustic emission. Cement and Concrete 
Research 42 (1) (2012) 61 - 73. doi:http://dx.doi.org/10.1016/j.cemconres.2011.07. 011.

URL http://www . sciencedirect. com/science/article/pii/S0008884611002110

[75] P. Rossi, N. Godart, J. Robert, J. Gervais, D. Bruhat, Investigation of the basic creep of concrete by acoustic emission, Materials and Structures 27 (9) (1994) 510-514. doi: 10.1007/BF02473211.

URL http://dx.doi.org/10.1007/BF02473211 